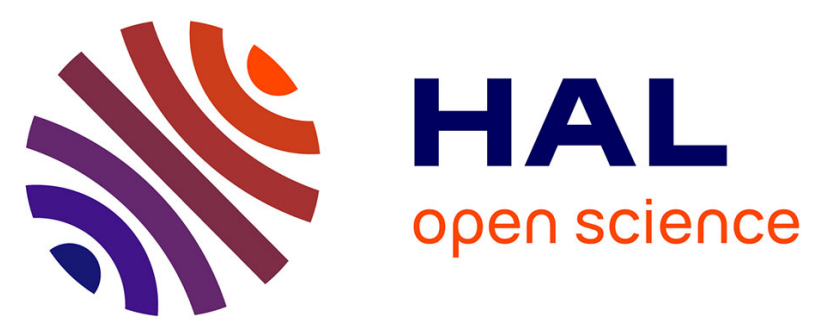

\title{
Improving GC-PPC-SAFT equation of state for LLE of hydrocarbons and oxygenated compounds with water.
}

Tran-Binh Nguyen, Jean-Charles de Hemptinne, Benoit Creton, Georgios M. Kontogeorgis

\section{- To cite this version: \\ Tran-Binh Nguyen, Jean-Charles de Hemptinne, Benoit Creton, Georgios M. Kontogeorgis. Improving GC-PPC-SAFT equation of state for LLE of hydrocarbons and oxygenated compounds with water.. Fluid Phase Equilibria, 2014, 372 (June), pp.113-125. 10.1016/j.fluid.2014.03.028 . hal-01030846}

\section{HAL Id: hal-01030846 \\ https: / hal-ifp.archives-ouvertes.fr/hal-01030846}

Submitted on 22 Jul 2014

HAL is a multi-disciplinary open access archive for the deposit and dissemination of scientific research documents, whether they are published or not. The documents may come from teaching and research institutions in France or abroad, or from public or private research centers.
L'archive ouverte pluridisciplinaire HAL, est destinée au dépôt et à la diffusion de documents scientifiques de niveau recherche, publiés ou non, émanant des établissements d'enseignement et de recherche français ou étrangers, des laboratoires publics ou privés. 


\title{
Improving GC-PPC-SAFT equation of state for LLE of hydrocarbons and oxygenated compounds with water
}

\author{
Thanh-Binh Nguyen ${ }^{\mathrm{a}, \mathrm{b}}$, Jean-Charles de Hemptinne ${ }^{\mathrm{b},{ }^{+}}{ }^{\text {, Benoit Creton }}{ }^{\mathrm{b}}$, \\ Georgios M. Kontogeorgis ${ }^{c}$
}

a Chemistry Engineering department, Da Nang University of Science and Technology, 54 Nguyen Luong Bang, Da Nang, Viet Nam

b IFP Energies nouvelles, 1-4 avenue de Bois-Préau, Rueil-Malmaison 92852, France

c Center for Energy Resources Engineering (CERE), Department of Chemical and Biochemical Engineering, Technical University of Denmark, DK-2800 Lyngby, Denmark

+ E-mail: j-charles.de-hemptinne@ifpen.fr

\begin{abstract}
The GC-PPC-SAFT model has been shown to be useful for predicting the liquidliquid phase split with water [Nguyen-Huynh et al. Ind. Eng. Chem. Res. 2011, 50, 7467-7483]. In order to extend the use of this model to oxygenated compounds for a large number of families (aliphatic ethers, aldehydes, ketones, formates, acetates, propionates/butyrates, n-aliphatic acids), it is proposed to consider cross-association in addition to a binary interaction parameter $1_{\mathrm{ij}}$ on the combining rules for the crosssegment diameter between water and the investigated compound.

The binary interaction parameters $l_{i j}, u_{\alpha \beta}$, and $w_{\alpha \beta}$ are fitted on mutual solubilities of water and organic compounds. The regressed values which are obtained for each chemical family, are subsequently used for predicting infinite dilution activity coefficient in water and n-octanol/water partition coefficient.

In general, the results obtained are very much improved compared to the predictive approach discussed previously [Nguyen et al. Ind. Eng. Chem. Res. 2013, 52, 7014-7029]. The global deviation values on the decimal log scale for infinite dilution activity coefficient in water, water solubility and n-octanol/water partition coefficient are $0.377,0.419$, and 0.469 , respectively.
\end{abstract}

Keywords: Group Contribution, GC-PPC-SAFT, binary interaction parameter, LLE, oxygenated compounds. 


\section{Introduction}

A reliable knowledge of the solubility of chemicals in various solvents, among which water has an important place, is of great importance for many fields of the chemical industry e.g. the areas of biorefining and environmental engineering. The liquidliquid equilibrium (LLE) properties serve also in the design and optimization of separation processes (e.g. liquid-liquid extraction, distillation). In this work, we have an extra focus on biorefining-related processes which are often faced with fluids covering a very large range of oxygenated compounds which are polar and hydrogen-bonding [1,2] As a consequence, the development of predictive approaches for phase equilibrium calculations is a major challenge, particularly for watercontaining mixtures with oxygenated compounds. Strongly associating and/or polar interactions between water and oxygen-bearing compounds (e.g. alcohols, acids, etc) are responsible for the extreme non-ideality of these mixtures. The modelling of these complex mixtures by applying cubic equations of state (EoS) with conventional mixing and combining rules is not appropriate[3,4] Many research efforts have been made in order to overcome this problem. Among these efforts, it is worth mentioning the so-called EoS/GE models which were initially proposed by Huron and Vidal[5,6]. The EoS/GE models, based on the combination of an EoS and an activity coefficient model (e.g. Wilson[7], NRTL,[8] UNIQUAC,[9] UNIFAC[10]), are mixing rules for the energy (and sometimes also the co-volume) parameters of an EoS. More details about this type of mixing and combining rules can be found in recent books $[11,13]$ and reviews. $[4,14,15]$ The application of the EoS/GE models for correlating water + chemicals (e.g. hydrocarbons, cyclohexanone, 1-butanol, surfactants, etc) LLE has been reported by some authors[16,19].

Another approach for modelling complex mixtures is to use EoS that account explicitly for associating and/or polar interactions between molecules. Many thermodynamic models have been proposed, such as APACT,[20] GCA-EoS,[21] 
SAFT,[22,23] CPA[24] or NRHB [25]. The Group Contribution Association Eos has been used with some success by Pereda et al. [26] [27] for describing phase equilibria of systems containing water, alkanes and alcohols. The most successful for the purpose of computing water + hydrocarbon LLE is CPA [28,30]. It has been extended to water + bio-oil mixtures by Oliveira et al.[31,32].

Using the SAFT theory, the first such paper was by Galindo et al.[33] who focused on the critical lines of water and n-alkanes. McCabe et al. [34] then showed that the infinite dilution properties could be adequately modelled as well with the same parameters. Using another version of SAFT, the group of Vega [35], and Patel et al.[36] also proposed a discussion on this subject. NguyenHuynh et al.[37] used the group-contribution polar PC-SAFT (GC-PPC-SAFT) approach to propose a predictive scheme on systems containing water, alkanes, aromatics and alcohols. Some other authors have used SAFT with water and oxygenated compounds, as Garcia-Lisbona et al. [38] on polyoxyethylene compounds, and Pedrosa et al. on glycols and polyethylene glycols [39,40].

Up to our knowledge, no systematic investigation was carried so far on the liquidliquid phase split of water with all oxygenated families. Yet, in bio-oils, one finds not only hydrocarbons and alcohols, but also esters, ethers, ketones, aldehydes and acids. The purpose of this work is therefore to extend the GC-PPC-SAFT approach for a large number of systems with transferable parameters in order to be able to extrapolate beyond the components considered.

There are many SAFT-type versions proposed e.g. the original SAFT [22,23], CKSAFT [41], the simplified SAFT,[42] LJ-SAFT,[43,44] soft-SAFT,[45] SAFT-VR,[46] PCSAFT[47], the simplified PC-SAFT[48], tPC-SAFT[49], and PPC-SAFT[50]. More details can be found in some references[13,51,52]. The main differences between these SAFT-type versions are mostly due to (1) the choice of the reference system, and (2) the choice of various descriptions for the repulsive and attractive interactions. 
Some authors extended these equations by adding a polar term to take into consideration the dipolar interactions between molecules $[44,45,50,53,56]$. The resulting polar SAFT models are of great interest in the modelling of oxygenated compounds/water mixtures. Successful modelling of various thermodynamic properties of many complex fluids and fluid mixtures by using SAFT-type versions has been reviewed in some references[13,57,58]. As discussed above, although several studies deal with the LLE behaviour as computed by SAFT-type models, particularly mutual solubilities, very few have investigated systematically several chemical families.

This work, which is the follow-up of our previous study,[59] proposes to use Group Contribution - Polar Perturbed Chain - SAFT (GC-PPC-SAFT) for computing LLE of water-containing mixtures with oxygenated compounds. This EoS, coupled with the GC concept of Tamouza et al.,[60] is an extension of the PC-SAFT model[47] for polar molecules[50]. More details will be given in the next section. In our previous work,[59] it was observed that the predictive capability of this model for calculating water solubility is very challenging. In addition, a sensitivity analysis indicated that a very small modification in the segment diameter could lead to very significant changes in solubility. To be concrete, a 5\% modification in the segment diameter caused an average absolute deviation of $314 \%$ in the prediction of the water solubility of oxygenated compounds. Because of the practical importance of this property, this paper will focus on an extension of the model that is based on the use of a binary interaction parameter on the cross-diameter parameter.

As for any thermodynamic model, mixing and combining rules are necessary for the GC-PPC-SAFT EoS when applied to mixtures. In SAFT models, as in many other EoS, a binary interaction parameter $k_{i j}$ is often used to correct the dispersion energy parameter $\varepsilon_{\mathrm{ij}}$, through the equation

$$
\varepsilon_{\mathrm{ij}}=\left(1-\mathrm{k}_{\mathrm{ij}}\right) \sqrt{\varepsilon_{\mathrm{i}} \varepsilon_{\mathrm{j}}}
$$


The use of this $k_{\mathrm{ij}}$ parameter was also a part of our previous work[59]. The physical meaning of $\mathrm{k}_{\mathrm{ij}}$ refers to the London's theory and several researchers have used this for proposing predictive methods for this parameter[61,64]. In general, these predictive approaches result in positive values for $k_{i j}$. As explained in the very interesting discussion by Haslam et al [62], negative values for this parameter can be found in polar mixtures: the polarity results in stronger attractive interactions than those that can be justified by the London dispersion forces, resulting in $\varepsilon_{\mathrm{ij}}>\sqrt{\varepsilon_{\mathrm{i}} \varepsilon_{\mathrm{j}}}$. Yet, in the polar versions of SAFT, the polarity effect is explicitly taken into consideration. Hence, the $\varepsilon_{\mathrm{ij}}$ parameter should represent only the London dispersion forces, which is why a Hudson \& McCoubrey[65]-type theory (implying positive $\mathrm{k}_{\mathrm{ij}}$ ) could be proposed by NguyenHuynh[63] in the PPC-SAFT framework. Yet, in some cases, it appears that still a negative value for this interaction parameter is unavoidable[66].

In this work, we have therefore investigated the path that was already used, but without any justification, by Held et al. $[67,68]$, which is the use of a correction parameter $1_{\mathrm{ij}}$ on the cross-diameter parameter $\sigma_{\mathrm{ij}}$. Schnabel et al. [61] propose a very interesting review of various combining rules and conclude that the so-called Lohrentz-Berthelot combining rule perform well on vapour-liquid equilibria and densities of a number of selected mixtures. Both Santos et al.[69] and Paricaud[70] propose an analysis of non-additive hard sphere and show that the use of this nonadditive character has a large effect on liquid-liquid phase split. This has motivated us to investigate the use of this type of binary interaction parameter, called $l_{\mathrm{ij}}$, with:

$$
\sigma_{\mathrm{ij}}=\frac{\sigma_{\mathrm{i}}+\sigma_{\mathrm{j}}}{2}\left(1-1_{\mathrm{ij}}\right)
$$

At this point, we should state that a few studies on the effect of $1_{i j}$ in the cross covolume parameter of cubic equations of state have been presented[13]. However, the 
$1_{\mathrm{ij}}$ in cubic EoS essentially affects the entropic part of the models that is actually not the case for SAFT models, as will become clear in sections 2.1 and 2.2 where the model equations are shown and this point is further discussed.

A second point that should be further investigated in this work is to revise the association scheme between water and oxygenated compounds. As shown in our previous work[59], the predictive capability of the GC-PPC-SAFT EoS on the solubilities was not correct for water with some oxygenated chemical families (i.e. aliphatic ethers, aldehydes, ketones, formates, acetates, propionates/butyrates, naliphatic acids) whose association parameters $\left(\varepsilon^{\mathrm{A}_{\alpha} \mathrm{B}_{\beta}}, \mathrm{K}^{\mathrm{A}_{\alpha} \mathrm{B}_{\beta}}\right)$ were all taken from that of alcohols, without further justification, originating from the work of NguyenHuynh et al[37]. The thermodynamic modelling of aqueous solutions of oxygenated compounds is not easily accessible due to the effect of the temperature on the crossassociating interaction between water and chemicals, as illustrated in Figure 1. At low temperatures, the cross-association degree between water and oxygenated compounds is strong, resulting in relatively higher mutual solubilities. When the temperature increases, the cross-association diminished and the self-association of water will take over resulting in decreased mutual solubilities. Finally, at high temperatures all association phenomena fade away resulting in an increased solubility. This discussion was already presented by Patel et al. [36], although they acknowledged the fact that this balance between self-and cross-association could not be invoked for water + alkane mixtures which was the subject of their study. In our case, such cross-association can be used, because the oxygenated groups are electrondonors in hydrogen bonds. This is why a specific effort will be devoted to optimize the cross-association between water and oxygenated compounds with the objective to improve the temperature dependence of the model. This will be further discussed in section 4 . 
The paper is organized as follows. Firstly, the GC-PPC-SAFT EoS and the determination of its parameters are described. The collection and treatment of experimental data are presented in section 3. Also in this section, the regression results of $1_{\mathrm{ij}}$ and the cross-association parameters $\mathrm{u}_{\alpha \beta} \& \mathrm{w}_{\alpha \beta}$ (defined below) are presented. In section 4 , the model is used to evaluate infinite dilution activity coefficients in water and n-octanol/water partition coefficient. Our conclusions are given at the end.

\section{GC-PPC-SAFT model}

\subsection{Model description}

The GC-PPC-SAFT model, namely Group Contribution - Polar Perturbed Chain Statistical Associating Fluid Theory, is the combination of the PPC-SAFT model[50] with the GC concept[71] in order to determine three parameters $\varepsilon / \mathrm{k}, \sigma$, and $\mathrm{m}$. This model is written as a sum of intermolecular contributions to the residual Helmholtz energy for given temperature, volume and composition, as shown in eq (3). These contributions are independent of each other.

$$
\mathrm{A}^{\text {res }}=\mathrm{A}^{\text {hs }}+\mathrm{A}^{\text {chain }}+\mathrm{A}^{\text {disp }}+\mathrm{A}^{\text {assoc }}+\mathrm{A}^{\text {multi-polar }}
$$

where $A^{\text {hs }}$ is the hard sphere term which accounts for repulsive interactions between hard spheres. This term is based on the hard-sphere theory developed by Boubli'k and Mansoori [72,73]. The most important parameter of this term is the segment diameter $\sigma$. The term $\mathrm{A}^{\text {chain }}$ describes the formation of the molecular chain, developed with the assumption of infinite association strength. The parameter $\mathrm{m}$ representing the number of segments in one molecular chain is the parameter of this term. In the PC-SAFT EoS, the reference term is the sum of the first and the second terms $\left(\mathrm{mA}^{\text {hs }}+\mathrm{A}^{\text {chain }}\right)$. The London-type attractive interactions between molecular chains are represented by the so-called dispersion term $\mathrm{A}^{\text {disp }}$. This term is constructed on the basis of the second-order perturbation theory of Barker and 
Henderson starting from a hard chain reference[74]. The characteristic parameter of this term is dispersive energy $\varepsilon / k$ (where $k$ is the Boltzmann constant) with units of temperature (in kelvin).

The contribution $\mathrm{A}^{\text {assoc }}$ in eq (3) originating from the Wertheim's theory is used for representing the hydrogen-bonding association. Its expression can be found in literature[75]. It is characterized by an association energy parameter $\varepsilon^{\mathrm{AB}}$ and an association volume parameter $\mathrm{K}^{\mathrm{AB}}$ (where $\mathrm{A}, \mathrm{B}$ are the associating sites). The last term $\mathrm{A}^{\text {multi-polar }}$ of eq (3) is used to take into consideration the polar interactions. Regarding the PPC-SAFT model, this term is based on the theory of Gubbins and Twu[76] for spherical molecules and the segment approach of Jog and Chapman[55]. The characteristic parameters of this term are the polar moments including the dipole $\mu$ and quadrupole $\mathrm{Q}$ moments and the corresponding polar fractions $\mathrm{mx}^{\mathrm{p} \mu}$ and $m x^{\mathrm{pQ}}$.

\subsection{Parameterization of the PPC-SAFT model}

a) Pure component parameters

By using the GC method of Tamouza et al.,[71] the three parameters of the PPCSAFT model ( $\varepsilon / \mathrm{k}, \sigma$, and $\mathrm{m}$ ) are calculated, as shown in eqs (4), (5), and (6).

$$
\begin{aligned}
& \varepsilon_{\text {molecule }}=\left(\sum_{\mathrm{i}=1}^{\mathrm{n}_{\text {groups }}} \sqrt[n_{\mathrm{i}}]{\prod_{\mathrm{i}=1}^{n_{\mathrm{n}}^{n_{\text {groups }}}} \varepsilon_{i}^{\mathrm{n}_{\mathrm{i}}}}\right. \\
& \sigma_{\text {molecule }}=\frac{\sum_{i=1}^{n_{\text {groups }}} n_{i} \sigma_{i}}{\sum_{i=1}^{n_{\text {groups }}} n_{i}} \\
& \mathrm{~m}_{\text {molecule }}=\sum_{\mathrm{i}=1}^{\mathrm{n}_{\text {groups }}} \mathrm{n}_{\mathrm{i}} \mathrm{R}_{\mathrm{i}}
\end{aligned}
$$


where $\varepsilon_{i}, \sigma_{i}$ represent the energy and diameter of the functional group $i$ in the molecule composed of $\mathrm{n}_{\text {groups }}$ different groups, respectively. $\mathrm{R}_{\mathrm{i}}$ is the contribution of functional group $\mathrm{i}$ to the chain length of the molecule. Its value depends on the position of functional group i in the molecule, as explained in reference[77].

The association and polarity parameters are family-specific parameters, or more exactly functional groups-specific parameters (e.g. hydroxyl group $\mathrm{OH}$ ). Within the GC scheme of the GC-PPC-SAFT EoS, these specific parameters are transferable within the entire family of molecules.

The reader is referred to our previous publication for further details about the parameterization of this model[59].

b) Mixture parameters

In order to apply the GC-PPC-SAFT model to mixtures, combining rules are required. Equations (1) and (2) are the so-called Lorentz-Berthelot combining rules for the dispersive energy $\varepsilon_{\mathrm{ij}}$ and segment diameter $\sigma_{\mathrm{ij}}$, when considering two different molecules $\mathrm{i}$ and $\mathrm{j}$. In this work, the binary interaction parameter $\mathrm{k}_{\mathrm{ij}}$ on the dispersive energy are taken as zero as observed in our previous work[78]. We will focus on the use of the non-additivity of the hard sphere diameters. The $1_{i j}$ values will be regressed as explained in the next section.

It is worth noting that although the non-additivity on the hard-sphere diameters may be interpreted as an entropic effect, it has no effect at all on the so-called 'hardsphere' term that originates from Boubli'k [72] and Mansoori [73] and uses only a generalized definition of the density $\zeta_{k}$ defined as:

$$
\zeta_{k}=\frac{\pi}{6} \frac{N_{A v}}{v}\left[\sum_{i=1}^{n} x_{i} m_{i}\left(d_{i i}\right)^{k}\right] .
$$


Here $k=1,2,3, v$ is the molar volume, $N_{A v}$ is Avogadro's number and dii represents the temperature dependent hard-sphere diameter:

$$
d_{i i}=\sigma_{i i}\left(1-0.12 \exp \left(-\frac{3 \varepsilon_{i i}}{k T}\right)\right) .
$$

No unlike interaction is involved here.

The unlike segment diameter instead comes into the equation through the dispersion term that uses mixing rules for $\mathrm{m}^{2} \varepsilon \sigma^{3}$ and $\mathrm{m}^{2} \varepsilon^{2} \sigma^{3}$ that appear in the first and second order contributions of the dispersion term:

$$
\begin{aligned}
& \overline{m^{2} \varepsilon \sigma^{3}}=\sum_{i}^{n} \sum_{j}^{n} x_{i} x_{j} m_{i} m_{j}\left(\frac{\varepsilon_{i j}}{k T}\right) \sigma_{i j}^{3} \\
& \overline{m^{2} \varepsilon^{2} \sigma^{3}}=\sum_{i}^{n} \sum_{j}^{n} x_{i} x_{j} m_{i} m_{j}\left(\frac{\varepsilon_{i j}}{k T}\right)^{2} \sigma_{i j}^{3}
\end{aligned}
$$

where $x_{i}, x_{j}$ are the mole fraction of components $i$ and $j$, respectively.

More details about the expressions can be found in the original paper[79].

This point essentially illustrates that $1_{\mathrm{ij}}$ in the cross diameter combining rule of SAFT model is very different from the $1_{\mathrm{ij}}$ in the cross co-volume of cubic EoS. First of all, the former refers to an interaction parameter in a segment-based combining rule while the latter is an interaction parameter in a molecular combining rule where covolume refers to the whole molecule. This may not even be the most significant difference. What is interesting is that the cross-diameter and subsequently the $1_{i j}$ enters in the SAFT equations only via eqs (9) \& (10). This means that $1_{\mathrm{ij}}$ in SAFT is not an entropic-related interaction parameter (as is clearly the case in cubic EoS) and it does not affect the reference term of the model. Via eqs (9) \& (10), it is clear that $1_{\mathrm{ij}}$ affects the dispersion term of the SAFT model, more or less in the same way as $k_{i j}$ 
but possibly even more significantly, as the cross diameter enters in the third power in these equations. In this interpretation, it makes sense to only use one of the two interaction parameters, as they have almost the same physical meaning and evidently they will be highly inter-correlated the way they enter in eqs (9) \& (10). Yet the choice of one rather than the other is here rather opportunistic as it is easier to justify a negative $\mathrm{l}_{\mathrm{ij}}$ rather than a negative $\mathrm{k}_{\mathrm{ij}}$.

As proposed by Derawi et al.[80] and Wolbach and Sandler,[81] equations (11) and (12) are combining rules for the association parameters in the case of crossassociating mixtures which contain two associating components (e.g. water and ketones).

$$
\varepsilon^{\mathrm{A}_{\alpha} \mathrm{B}_{\beta}}=\frac{\varepsilon^{\mathrm{A}_{\alpha}}+\varepsilon^{\mathrm{B}_{\beta}}}{2}\left(1-\mathrm{w}_{\alpha \beta}\right)
$$

and

$$
\mathrm{K}^{\mathrm{A}_{\alpha} \mathrm{B}_{\beta}}=\sqrt{\mathrm{K}^{\mathrm{A}_{\alpha}} \mathrm{K}^{\mathrm{B} \beta}}\left(1-\mathrm{u}_{\alpha \beta}\right)
$$

where the superscripts A and B represent the associating sites on the different functional groups $\alpha$ or $\beta$. It should be noted that parameters are directly grouprelated parameters, and as such, they are fully transferable within a chemical family. Additional interaction parameters $\left(\mathrm{u}_{\alpha \beta}\right.$ and $\left.\mathrm{w}_{\alpha \beta}\right)$ are also used to correct the given combining rules when the groups $\alpha$ and $\beta$ belong to different chemical families. Note that it would be more correct to use $u_{A_{\alpha} B_{\beta}}$ and $w_{A_{\alpha} B_{\beta}}$, since the interactions are truly site-site and not group-group. Yet, in this work, all sites on the same group carry identical parameters, so we have simplified the notation. Except for (alcohols + water) and (n-alkylbenzenes + water) mixtures whose cross-association parameters were studied by Nguyen-Huynh et al.[37], we consider in this work cross-association parameters between water and other oxygenated compounds (the oxygen atom always contains a free electron pair that makes it possible to hydrogen bond with 
water). These families include aliphatic ethers, aldehydes, ketones, formates, acetates, propionates/butyrates, n-aliphatic acids.

Table 1 summarizes the PPC-SAFT parameters for different oxygenated families studied in this work. All details of the parameterization of this model (using group contribution approach) are provided in our previous paper[59]. Also in Table 1, the PPC-SAFT parameters of two solvents (water and n-octanol) which are considered in this work are presented. These parameters are re-used from our previous work[59].

\section{Regression results}

\subsection{Experimental data}

Experimental data for mutual solubilities of water/oxygenated compounds mixtures $\left(x_{i}^{\text {aq }}, x_{i}^{\text {org }}\right)$, infinite dilution activity coefficient in water $\left(\gamma_{i}^{\text {aq, }, \infty}\right)$, and n-octanol/water partition coefficient $\left(\mathrm{K}_{\mathrm{OW}}\right)$ are firstly collected for the purposes of regression and evaluation. Table 2 summarizes the number of molecules for which data of $x_{i}^{\text {aq }}, \gamma_{i}^{\text {aq, }, \infty}$, and $\mathrm{K}_{\mathrm{ow}}$ are available. These data are re-used from our earlier work. [59]

The experimental data of $\mathrm{x}_{\mathrm{i}}^{\text {org }}$, originating from the DETHERM database,[82] are gathered for some oxygenated chemical families i.e. acetates, formates, propionates/butyrates, aldehydes, aliphatic ethers, ketones, n-aliphatic acids. A summary of the data for this property is given in

Table 3.

To make the use of these data easier, all properties considered in this work are correlated for each compound as a function of temperature, as shown in eq (13).

$$
\log X=A_{x}+\frac{B_{x}}{T}+C_{x} \log (T)
$$


where $X$ is the property to be correlated (i.e. $x_{i}^{\text {aq }}, x_{i}^{\text {org }}, \gamma_{i}^{\text {aq, }, \infty}$ ) and $A_{x}, B_{x}, C_{x}$ are adjusted coefficients which are fitted to experimental data by using the "datafit" function provided with Scilab software[83]. The numerical values of $A_{x}, B_{x}, C_{x}$ and the validated range of temperature $\left(T_{\min }, T_{\max }\right)$ for each compound are detailed in the Supporting Information (Correlations.Results.xls). Note that the correlations of $\mathrm{x}_{\mathrm{i}}^{\mathrm{aq}}, \gamma_{\mathrm{i}}^{\mathrm{aq}, \infty}$, and $\mathrm{K}_{\mathrm{OW}}$ are re-used from our earlier work. [59] In addition, because there are not enough $\mathrm{K}_{\mathrm{ow}}$ data to evaluate its temperature dependence, eq (13) is only reported with $A_{x}$ which is actually the $K_{o w}$ value measured at $298.15 \mathrm{~K}$. It should be also noted that when constructing these correlations, the deviation with the experimental values are also evaluated in order to have an estimate of the uncertainties of the data.

\subsection{Regression for $l_{i j}, u_{\alpha \beta}$, and $w_{\alpha \beta}$}

Our previous studies pointed out that the solubility in water was correctly calculated in a purely predictive way for hydrocarbons and alcohols, but the predictive capability of the GC-PPC-SAFT model was not correct for other oxygenated compounds[59]. That's why this study is only concentrated on improving the predictive scheme for oxygenated families excluding n-alcohols, other aliphatic alcohols, and n-alkylbenzenes which were investigated by Nguyen-Huynh et al[37].

The $1_{i j}, u_{\alpha \beta}$, and $w_{\alpha \beta}$ values are fitted for each oxygenated chemical family, consisting of aliphatic ethers, aldehydes, ketones, formates, acetates, propionates/butyrates, n-aliphatic acids, to the mutual solubilities of water and oxygenated compounds by minimizing the following objective function:

$$
\mathrm{OF}=\frac{1}{\mathrm{n}} \sum_{\mathrm{i}=1}^{\mathrm{n}}\left(\frac{\mathrm{x}_{\mathrm{i}}^{\mathrm{aq}, \text { exp }}-\mathrm{x}_{\mathrm{i}}^{\text {aq, calc }}}{\mathrm{x}_{\mathrm{i}}^{\text {aq,exp }}}\right)^{2}+\frac{1}{\mathrm{n}^{\prime}} \sum_{\mathrm{j}=1}^{\mathrm{n}^{\prime}}\left(\frac{\mathrm{x}_{\mathrm{i}}^{\text {org,exp }}-\mathrm{x}_{\mathrm{i}}^{\text {org, calc }}}{\mathrm{x}_{\mathrm{i}}^{\text {org,exp }}}\right)^{2}
$$


where $x_{i}^{\text {aq,exp }}$ and $x_{i}^{\text {aq, calc }}$ are experimental and calculated solubilities of oxygenated compounds in water, respectively. $x_{i}^{\text {org,exp }}$ and $x_{i}^{\text {org,calc }}$ are experimental and calculated solubilities of water in organic phase, respectively. $n, n^{\prime}$ are the number of experimental points created by using eq (13). The values of $n, n^{\prime}$ equal 11 for each property in the allowed range of temperature. It should be noted that the calculation is performed without using the predictive $\mathrm{k}_{\mathrm{ij}}$ given by Nguyen-Huynh et al[63,64].

The estimated values of $1_{i j}, u_{\alpha \beta}$, and $w_{\alpha \beta}$ are presented in Table 4. Generally, the $1_{\mathrm{ij}}$ values are estimated to be between -0.006 and -0.019 which correspond to an increase of the segment diameter $\sigma_{\mathrm{ij}}$ in the range of $0.6 \%$ to $2 \%$. Note that $\mathrm{u}_{\alpha \beta}$ and $\mathrm{W}_{\alpha \beta}$ are presented through the values of the cross-association parameters $\left(\varepsilon^{\mathrm{A}_{\alpha} \mathrm{B}_{\beta}} \&\right.$ $\mathrm{K}^{\mathrm{A}_{\alpha} \mathrm{B}_{\beta}}$ ) between the oxygenated families and water that are actually affected by these two correction parameters. The cross-association parameters of oxygenated family and water are calculated by using the combining rules as shown in eqs (11) \& (12). In order to evaluate the values of $\varepsilon^{\mathrm{A}_{\alpha} \mathrm{B}_{\beta}} \& \mathrm{~K}^{\mathrm{A}_{\alpha} \mathrm{B}_{\beta}}$ in Table 4, we calculate the so-called association strength present in the association term of the PPC-SAFT EoS. Equation (15) presents its expression as a function of temperature:

$$
\Delta^{\mathrm{A}_{\alpha} \mathrm{B}_{\beta}}=\mathrm{D}_{\mathrm{ij}}^{3} \mathrm{~g}_{\mathrm{ij}}^{\mathrm{hs}} \mathrm{K}^{\mathrm{A}_{\alpha} \mathrm{B}_{\beta}}\left[\exp \left(\frac{\varepsilon^{\mathrm{A}_{\alpha} \mathrm{B}_{\beta}}}{\mathrm{kT}}\right)-1\right]
$$

where $\Delta^{\mathrm{A}_{\alpha} \mathrm{B}_{\beta}}$ is the association strength; $\mathrm{k}$ is Boltzmann factor; $\mathrm{T}$ is temperature; $\mathrm{g}_{\mathrm{ij}}^{\text {hs }}$ is radial distribution function given according to Boubli'k [72] and Mansoori [73] as:

$$
g_{i j}^{h s}=\frac{1}{1-\zeta_{3}}+3 \frac{d_{i j} \zeta_{2}}{\left(1-\zeta_{3}\right)^{2}}+2 \frac{\left(d_{i j} \zeta_{2}\right)^{2}}{\left(1-\zeta_{3}\right)^{3}}
$$

and $\mathrm{D}_{\mathrm{ij}}$ is an average diameter defined as $D_{i j}=\frac{d_{i i}+d_{j j}}{2}$. Note that $l_{\mathrm{ij}}$ has no effect here because the average is performed on the temperature-dependent diameters. 
In order to simplify the calculation (diameter and radial distribution function depend only slightly on volume), the association strength $\Delta^{\mathrm{A}_{\alpha} \mathrm{B}_{\beta}}$ will be calculated as $\frac{\Delta^{A_{\alpha} B_{\beta}}}{D_{i j}^{3} g_{i j}^{h s}}$ at various temperatures. Figure 2 shows the calculated cross-association strengths for 7 chemical families i.e. aliphatic ethers, aldehydes, ketones, formates, acetates, propionates/butyrates, and n-aliphatic acids. The values for n-alcohols, other aliphatic alcohols, n-alkylbenzenes are taken directly from the work of Nguyen-Huynh et al.[84] Figure 2 shows the trend of association energies as a function of the functional group: the order follows that of the expected association energies. The values of n-aliphatic acids are extremely large, testifying that the acids have a very strong interaction with water. Next are alcohols, aliphatic ethers, aldehydes, ketones and esters. The aliphatic ethers have a low interaction, probably because their lone electron pair is not well accessible, and n-alkylbenzenes have a very small interaction with water.

\section{Evaluation on $x_{i}^{\text {aq }}, x_{i}^{\text {org }}, \gamma_{i}^{\text {aq, }, \infty}$, and $K_{o w}$}

Using the regressed parameter values, an evaluation of the performance of the model for $x_{i}^{\text {aq }}, x_{i}^{\text {org }}, \gamma_{i}^{\text {aq, }, \infty}$, and $\mathrm{K}_{\mathrm{ow}}$ is carried out. The evaluation is performed by comparing the values computed by the model and the experimental values which are generated from eq (13) within an allowed temperature range. The deviation between the computed results and experimental data is expressed by using the standard error $\left(\mathrm{SE}^{\mathrm{SAFT}}\right)$ that was also used in our previous paper[59].

$$
S E^{\mathrm{SAFT}}=\sqrt{\frac{\sum_{\mathrm{i}=1}^{\mathrm{n}}\left(\log X_{\mathrm{i}}^{\mathrm{SAFT}}-\log \mathrm{X}_{\mathrm{i}}^{\mathrm{Corr}}\right)^{2}}{\mathrm{n}-1}}
$$

where $\log \mathrm{X}_{\mathrm{i}}^{\mathrm{SAFT}}$ and $\log \mathrm{X}_{\mathrm{i}}^{\text {Corr }}$ correspond to the values predicted by the GC-PPCSAFT model and calculated from the correlations of the experimental data (eq (13)), respectively. Each property is evaluated at 11 different temperatures and therefore $n$ 
$=11$, except for $\mathrm{K}_{\mathrm{OW}}$, for which data only exist at $298.15 \mathrm{~K}$. In the latter case, the logarithmic absolute deviation between the experimental and predicted values is used. This definition is similar to the eq (16) with $\mathrm{n}=1$ and without the denominator. We still call this deviation $\mathrm{SE}^{\mathrm{SAFT}}$. The reason for using the logarithmic values in eq (16) is related to the fact that the data considered cover a very large range of orders of magnitude ranging from $10^{0}$ to $10^{11}$. It should be noted that $\mathrm{SE}^{\mathrm{SAFT}}=1$ is equivalent to a factor of 10 in deviation between the measured and model calculated values. For small values, $\mathrm{SE}^{\mathrm{SAFT}}$ values can be compared to the well-known relative deviations multiplying with 2.3 (e.g. $\mathrm{SE}^{\mathrm{SAFT}}=0.04$ is equivalent with a relative deviation of $10 \%$ ).

In what follows, two different approaches are compared:

- the so-called "predictive" approach (called Case 1), which uses the group contribution pure component parameters, and $\mathrm{k}_{\mathrm{ij}}=0$ (note that this is not the "predictive approach" of the original paper by Nguyen-Huynh[37,63] that computes $\mathrm{k}_{\mathrm{ij}}$ using pseudo-ionization energies, even though the results are almost identical). This approach was already presented in the previous paper[78]. It should be noticed that in the "predictive" approach the crossassociation parameters $\left(\varepsilon^{\mathrm{A}_{\alpha} \mathrm{B}_{\beta}}\right.$ and $\mathrm{K}^{\mathrm{A}_{\alpha} \mathrm{B}_{\beta}}$ ) of water and oxygenated compounds (aliphatic ethers, aldehydes, ketones, formates, acetates, propionates/butyrates, n-aliphatic acids) are not zero but taken from those of alcohols from the work of Nguyen-Huynh et al.[84] without further justification.

- the " $1_{\mathrm{ij}}, \mathrm{u}_{\alpha \beta}$, and $\mathrm{w}_{\alpha \beta}$ " approach (called Case 2), which uses the three parameters $1_{\mathrm{ij}}, \mathrm{u}_{\alpha \beta}$, and $\mathrm{w}_{\alpha \beta}$.

- In addition, whenever possible, these results are compared with the experimental uncertainties of the data (called Case 3). These have been 
obtained by evaluating the average deviation between the raw data and the correlation used in eq (13). More detail are available in our previous paper[78].

\subsection{Solubilities}

Firstly, we present the evaluation results for solubilities which are also used in the parameter estimation of the set of $1_{i j}, u_{\alpha \beta}$, and $w_{\alpha \beta}$ (Case 2). Figure 3 and Figure 4 show $\mathrm{SE}^{\text {SAFT }}$ for each chemical family for mutual solubilities i.e. $x_{i}^{\text {org }}$ and $x_{i}^{\text {aq }}$, respectively. More details are presented in

Table 5.

As expected, the use of the $1_{\mathrm{ij}}$ values with the new cross-association parameters (Case 2) improved the calculations for both solubilities ( $x_{i}^{\text {org }}$ and $\left.x_{i}^{\text {aq }}\right)$ as compared to the results of the "predictive" approach. In general, the use of $u_{\alpha \beta}$ and $w_{\alpha \beta}$ has not much impact on the solubilities of water in the organic phase $x_{i}^{\text {org }}$, except for aliphatic ethers and n-aliphatic acids. The calculation of $x_{i}^{\text {org }}$ for formates is worse when using $1_{\mathrm{ij}}$ with the improved cross-association parameters ( $\mathrm{x}_{\mathrm{i}}^{\mathrm{aq}}$ is strongly improved). The mean $\mathrm{SE}^{\mathrm{SAFT}}$ values for $\mathrm{x}_{\mathrm{i}}^{\text {org }}$ are $0.187,0.160$ corresponding to the case 1 and case 2, respectively. Regarding the solubilities of oxygenated compounds in water $x_{i}^{\text {aq }}$, the mean $S E^{\text {SAFT }}$ values in the case of using $1_{i j}$ with the improved crossassociation parameters equals 0.419 (an average of $60 \%$ deviation). The result is much improved as compared to the predictive approach with $\mathrm{SE}^{\mathrm{SAFT}}=1.103$ (an average of $90 \%$ deviation), particularly in the case of n-aliphatic acids, propionates/butyrates, aliphatic ethers, formates. 
Yet, these average values do not show the full picture, which can only be appreciated when considering the temperature dependence of these solubilities as shown in Figure 5. These figures show that the improved model almost always crosses the experimental trend. Yet, while according to the model both solubilities always increases with temperature, the experimental behaviour may be opposite. In the case of di-n-butyl ether, for example, while the solubility of water in the organic phase increases with temperature (this is the observed trend for all chemicals investigated), the solubility of the chemicals in water decreases with temperature. As discussed previously, the balance between cross- and self-association that is proposed by SAFT should make it possible to describe a solubility curve that exhibits a minimum. Yet, several phenomena make it difficult for SAFT to capture this behaviour. First, no such minimum is observed for the water solubility in the organic phase; second, the location of the minimum varies within a chemical family, probably because of experimental uncertainties. As a consequence, while the model predictive capacity has been clearly improved (it is capable of describing the correct order of magnitudes of both solubilities), a more fundamental investigation will be needed for improving the detailed shape of the curves.

\subsection{Infinite dilution activity coefficient in water}

On the basis of the regressed values, we now evaluate the predictive capability of the GC-PPC-SAFT model on infinite dilution activity coefficient in water $\gamma_{i}^{\text {aq, } \infty}$. The results are presented in Figure 6 and details are provided in Table 6.

As expected, the predictive capability of the GC-PPC-SAFT model for infinite dilution activity coefficient in water $\gamma_{i}^{\mathrm{aq}, \infty}$ is better when the $1_{\mathrm{ij}}$ values with the new cross-association parameters are used. Considering the results per family, we observe significant improvements as compared to the predictive approach, for all chemical families. The mean SE ${ }^{\mathrm{SAFT}}$ values are $0.991,0.377$ corresponding to "predictive", " $1_{\mathrm{ij}}+$ $\mathrm{u}_{\alpha \beta}+\mathrm{w}_{\alpha \beta}$ " approaches, respectively. In general, the trend of results is the same for 
two solubilities i.e. $\gamma_{i}^{\mathrm{aq}, \infty}$ and $\mathrm{x}_{i}^{\mathrm{aq}}$. This is fully expected because we have for poorly soluble systems $x_{i}^{\mathrm{aq}} \approx \frac{1}{\gamma_{\mathrm{i}}^{\mathrm{aq}, \infty}}$.

Figure 7 presents some examples for the prediction of $\gamma_{i}^{\mathrm{aq}, \infty}$ with the use of regressed values as a function of temperature. The order of magnitude of this property can be correctly described, but it is sometimes much more difficult to represent the correct slope of these plots. Comparing these plots of $\gamma_{i}^{\mathrm{aq}, \infty}$ with $\mathrm{x}_{i}^{\mathrm{aq}}$ in

Figure 5, the validity of the correlation $x_{i}^{\text {aq }} \approx \frac{1}{\gamma_{i}^{\text {aq }, \infty}}$ becomes visible. Hence, the explanation of this figure is identical to that of Figure 5.

\section{3 n-octanol/water partition coefficient}

Finally, we consider the n-octanol/water partition coefficient $\mathrm{K}_{\mathrm{Ow}}$, again using the same regressed values as discussed above (the values presented in Table 4), obtained from mutual solubilities. The results are presented in Figure 8 and in more detail in Table 6.

The best results are obtained when the previously regressed values are used. The global $\mathrm{SE}^{\mathrm{SAFT}}$ value is 0.469 (using the cross-association parameters), in comparison to 1.060 in the case of using no regressed values.

Figure 9 is the parity diagram for comparing measured and predicted $\mathrm{K}_{\mathrm{OW}}$. The values are predicted by using " $1_{\mathrm{ij}}+\mathrm{u}_{\alpha \beta}+\mathrm{w}_{\alpha \beta}$ " approach, excluding $\mathrm{n}$-alcohols and nalkanes. The calculated values of n-alcohols and n-alkanes are taken directly from our previous work[59]. It should be noted that $\mathrm{K}_{\mathrm{ow}}$ of $\mathrm{n}$-alcohols is calculated by using the cross-association of Nguyen-Huynh et al[37]. A good prediction is observed for almost all chemical families considered in this work. The results are also good for n-alcohols and n-alkanes having small molecular weight. However, larger deviations are observed for some heavy molecules, particularly n-aliphatic acids, 
alcohols and n-alkanes with more than 10 carbon atoms. Figure $\mathbf{1 0}$ shows the trends for these chemical families as a function of the number of carbon atoms, both according to the data and the model. It is expected that all trends converge as the number of carbon atoms increase because the functional group is then "diluted" in the aliphatic chain. This is observed for aliphatic acids and n-alkanes data, but not for the n-alcohols whose $\mathrm{K}_{\mathrm{ow}}$ is much smaller than the observations for $\mathrm{n}$-aliphatic acids and n-alkanes.

In order to understand the observed deviations, the $\mathrm{K}_{\mathrm{ow}}$ behaviour can be analyzed using the definition of n-octanol/water partition coefficient, as shown in eq (17).

$$
\mathrm{K}_{\mathrm{OW}}=\lim _{\mathrm{x}_{\mathrm{i}} \rightarrow 0} \frac{\mathrm{c}_{\mathrm{i}}^{\text {Oct }}}{{\mathrm{c}_{\mathrm{i}}^{\mathrm{aq}}}^{\mathrm{aq}}}=\frac{\mathrm{x}_{\mathrm{i}}^{\text {Oct }} \mathrm{v}^{\mathrm{aq}}}{\mathrm{x}_{\mathrm{i}}^{\mathrm{aq}} \mathrm{v}^{\text {Oct }}}=\frac{\gamma_{i}^{\mathrm{aq}, \infty} \mathrm{v}^{\mathrm{aq}}}{\gamma_{\mathrm{i}}^{\text {Oct, } \infty} \mathrm{v}^{\text {Oct }}}
$$

Equation (17) shows that several quantities affect directly the results:

- the infinite dilution activity coefficients in water $\gamma_{i}^{\text {aq, }, ~}$, which we have analyzed above. The numerical values may be slightly because values used here originate from a liquid-liquid phase split calculation for a ternary mixture containing water, n-octanol and the chemical under investigation. Hence, the water phase is not pure as before, it contains a small amount of $\mathrm{n}$-octanol (molar fraction of n-octanol in water at $298.15 \mathrm{~K}=2 \mathrm{ppm}$ ). The chemical is always considered at infinite dilution.

- the ratio of molar volumes $\mathrm{v}^{\mathrm{aq}} / \mathrm{v}$ oct of the two solvents. In our calculation, this ratio is the result of the GC-PPC-SAFT calculation, which yields at $298.15 \mathrm{~K} \mathrm{v}^{\text {aq }} / \mathrm{v}_{\text {oct }}=0.14$. The experimental value for this ratio is $\mathrm{v}^{\text {aq }} / \mathrm{v}_{\text {Oct }}=0.11$. This mistake will lead to an error of $21 \%$ on $\mathrm{K}_{\mathrm{ow}}$, much less than that 
observed on Table 6. The calculations have been performed again with the experimental ratio, but no major change can be seen on the $\mathrm{K}_{\mathrm{ow}}$ results.

- the infinite dilution activity coefficient in n-octanol $\gamma_{i}^{\text {Oct, }, \infty}$. In order to evaluate the quality of the predictions in this type of solvent, we have further investigated a number of alkane + n-octanol binary systems, as shown in Figure 11. It appears that the GC-PPC-SAFT results agree with experimental data. The deviations in logarithmic units are at most 0.1 . We should note that the n-octanol phase contains a non-negligible amount of water $(\approx 14 \%)$, but we have tested the effect of this concentration on the alkane activity coefficient and found a very small effect through the reconstruction of "pseudo-experimental" $\mathrm{K}_{\mathrm{ow}}$ on the basis of the experimental data of $\gamma_{\mathrm{i}}^{\mathrm{Oct}, \infty}$ and $\gamma_{\mathrm{i}}^{\mathrm{aq}, \infty}$ using eq (17) (Figure 12).

Figure 12 presents the comparison between the experimental, pseudoexperimental and calculated values for $\mathrm{K}_{\mathrm{ow}}$ of $\mathrm{n}$-alkanes families.

It is found that the values calculated by the GC-PPC-SAFT model are very consistent with the pseudo-experimental data. There is a large deviation between the experimental data and the predicted values. On the basis of the results on Figure 10 and Figure 12, the large deviation observed on n-alkanes, n-aliphatic acids and alcohols seems to point to inaccuracy in the data. It should be recalled that $K_{o w}$ is often measured for evaluating the toxicity of a chemical in the environment ecosystems. The type of measurements and their conditions may be quite different from those considered in thermodynamic calculations. This may explain the observed disagreements, but more measurements will be needed in order to clarify the question. 


\section{Conclusion}

The overall objective of this work is to evaluate the performance and especially the predictive capability of the GC-PPC-SAFT model for LLE-type properties $\left(x_{i}^{\text {org }}, x_{i}^{\text {aq }}\right.$, $\gamma_{\mathrm{i}}^{\mathrm{aq}, \infty}, \mathrm{K}_{\mathrm{OW}}$ ) of oxygenated compounds/water mixtures using a binary interaction parameter $1_{i j}$, which is a correction on the combining rule for the segment diameter, together with the improved cross-association parameters.

The use of $\left(l_{i j}+u_{\alpha \beta}+w_{\alpha \beta}\right)$ approach improved significantly the predictive capability of the model for the LLE-type properties of oxygenated chemical families i.e. aliphatic ethers, aldehydes, ketones, formates, acetates, propionates/butyrates, and n-aliphatic acids.

In general, the performance of the GC-PPC-SAFT model for infinite dilution activity coefficient in water and n-octanol/water partition coefficient is very encouraging considering the predictive nature of many calculations and the very extensive database used. The results with the GC-PPC-SAFT model are much improved when the three parameters $1_{i j}, u_{\alpha \beta}$, and $w_{\alpha \beta}$ are used.

Table 1. PPC-SAFT parameters for different chemical families a

\begin{tabular}{lccccccccc}
\hline \multicolumn{1}{c}{ Chemical family } & $\begin{array}{c}\varepsilon / \mathrm{k} \\
(\mathrm{K})\end{array}$ & $\begin{array}{c}\sigma \\
(\mathrm{A})\end{array}$ & $\begin{array}{c}\mathrm{m} \\
(-)\end{array}$ & $\begin{array}{c}\varepsilon^{\mathrm{AB}} / \mathrm{k} \\
(\mathrm{K})\end{array}$ & $\begin{array}{c}\mathrm{K}^{\mathrm{AB}} \\
(-)\end{array}$ & $\begin{array}{c}\mathrm{n}_{\text {sites }} \\
(-)\end{array}$ & $\begin{array}{c}\text { charges } \\
(-)\end{array}$ & $\begin{array}{c}\mu \\
{[\mathrm{D}]}\end{array}$ & $\begin{array}{c}\mathrm{mx}^{\mathrm{p \mu}} \\
(-)\end{array}$ \\
\hline Water [37] & 218.79 & 3.3845 & 0.8096 & 1813 & 0.0356 & 4 & ++- & 1.85 & 0.295 \\
n-octanol [59] & 256.65 & 3.76 & 0.81 & 2143.3 & 0.0088 & 3 & +- & 1.7 & 0.5 \\
aliphatic ethers & $\mathrm{GC}$ & $\mathrm{GC}$ & $\mathrm{GC}$ & $1978.2^{\mathrm{e}}$ & $0.0175^{\mathrm{e}}$ & 1 & - & 1.2 & 1.20 \\
aldehydes & $\mathrm{GC}$ & $\mathrm{GC}$ & $\mathrm{GC}$ & $1978.2^{\mathrm{e}}$ & $0.0175^{\mathrm{e}}$ & 1 & - & $\mathrm{c}$ & 0.60 \\
ketones & $\mathrm{GC}$ & $\mathrm{GC}$ & $\mathrm{GC}$ & $1978.2^{\mathrm{e}}$ & $0.0175^{\mathrm{e}}$ & 1 & - & 2.7 & 0.57 \\
acetates & $\mathrm{GC}$ & $\mathrm{GC}$ & $\mathrm{GC}$ & $1978.2^{\mathrm{e}}$ & $0.0175^{\mathrm{e}}$ & 1 & - & $\mathrm{d}$ & 1.15 \\
propionates/butyrates & $\mathrm{GC}$ & $\mathrm{GC}$ & $\mathrm{GC}$ & $1978.2^{\mathrm{e}}$ & $0.0175^{\mathrm{e}}$ & 1 & - & $\mathrm{d}$ & 1.15
\end{tabular}




\begin{tabular}{llllllllll} 
formates & GC & GC & GC & $1978.2^{\mathrm{e}}$ & $0.0175^{\mathrm{e}}$ & 1 & - & 1.9 & 1.20 \\
n-aliphatic acids & GC & GC & GC & 6085.5 & 0.0010 & 1 & $0^{\mathrm{f}}$ & 1.5 & 1.00 \\
\hline
\end{tabular}

a More details can be found in the supplementary material (SAFTBANK.xls). Notations: $\varepsilon / \mathrm{k}, \sigma, \mathrm{m}, \varepsilon^{\mathrm{AB}} / \mathrm{k}$, $\mathrm{K}^{\mathrm{AB}}, \mathrm{n}_{\text {sites }}, \mu, \mathrm{mx}^{\mathrm{p \mu}}$ correspond to dispersive energy, segment diameter, chain length, association energy, association volume, number of association sites, dipolar moment, dipolar fraction. b GC: the values are calculated by using eqs (4), (5), and (6). c,d the values are calculated using the formulas proposed by NguyenHuynh et al.[50] e Cross-association parameters with water calculated by using eqs (11) and (12). ${ }^{\mathrm{f}}$ charge zero means that the site may associate with any other site, be it zero, positive or negative.

Table 2. Summary of the number of molecules for which data are used in this study, per family. Data are taken from DETHERM database[82] and from other sources[85,92].

\begin{tabular}{|c|c|c|c|c|}
\hline Chemical family & & $\mathbf{x}_{\mathrm{i}}^{\mathrm{aq}}$ & $\gamma_{\mathrm{i}}^{\mathrm{aq}, \infty}$ & $\mathbf{K}_{\mathrm{ow}}$ \\
\hline acetates & & 13 & 13 & 5 \\
\hline aldehydes & & 7 & 7 & 5 \\
\hline aliphatic ethers & & 12 & 10 & 4 \\
\hline formats & & 7 & 7 & 2 \\
\hline ketones & & 18 & 18 & 11 \\
\hline n-alcohols & & 13 & 14 & 11 \\
\hline n-aliphatic acids & & 8 & 8 & 8 \\
\hline other aliphatic alcohols & & 13 & 15 & 12 \\
\hline propionates / butyrates & & 10 & 10 & 6 \\
\hline & Total & 101 & 102 & 64 \\
\hline
\end{tabular}

Table 3. Summary of the experimental data for solubilities of water in oxygenated compounds. The data are taken from DETHERM database[82].

\begin{tabular}{lcccc}
\hline \multicolumn{1}{c}{ Chemical family } & $\begin{array}{c}\mathbf{n}^{\circ} \text { of } \\
\text { molecules }\end{array}$ & $\begin{array}{c}\mathbf{n}^{\circ} \text { of exp. } \\
\text { points }\end{array}$ & $\begin{array}{c}\text { range of } \\
\text { carbon atoms }\end{array}$ & $\begin{array}{c}\text { range of } \\
\text { temperature }\end{array}$ \\
\hline Aliphatic ethers & 11 & 127 & $4-8$ & $273.15-368.15$ \\
Aldehydes & 7 & 74 & $3-9$ & $273.15-363.15$ \\
Ketones & 14 & 186 & $5-9$ & $273.15-453.15$ \\
Formates & 6 & 40 & $3-9$ & $273.15-363.75$ \\
Acetates & 13 & 211 & $4-10$ & $273.15-413.75$ \\
Propionates/Butyrates & 10 & 89 & $4-9$ & $273.15-363.85$ \\
n-aliphatic acids & 4 & 23 & $5-11$ & $291.15-545.65$ \\
\hline
\end{tabular}


Table 4. Values of $1_{i j}$ and the cross-association parameters $\left(\varepsilon^{A_{\alpha} B_{\beta}}\right.$ and $\left.K^{A_{\alpha} B_{\beta}}\right)$ for oxygenated compounds/water mixtures.

\begin{tabular}{lccc}
\hline \multicolumn{1}{c}{ Chemical family } & $\begin{array}{c}\mathbf{l}_{\mathrm{ij}} \\
(-)\end{array}$ & $\begin{array}{c}\boldsymbol{\varepsilon}^{\mathrm{AB}} / \mathbf{k}^{\mathbf{b}} \\
{[\mathbf{K}]}\end{array}$ & $\begin{array}{c}\mathbf{K}^{\mathrm{AB}} \mathbf{b} \\
\mathbf{( - )}\end{array}$ \\
\hline Aliphatic ethers & -0.01872 & 1978.15 & 0.0077 \\
Aldehydes & -0.00582 & 1905.90 & 0.0201 \\
Ketones & -0.01099 & 1699.50 & 0.0353 \\
Formates & -0.01348 & 1313.63 & 0.1066 \\
Acetates & -0.00943 & 1504.94 & 0.0744 \\
Propionates/Butyrates & -0.01722 & 1828.37 & 0.0208 \\
Aliphatic acids & -0.01886 & 4146.93 & 0.0034 \\
n-alcohols a & -- & 1978.15 & 0.0220 \\
Other aliphatic alcohols ${ }^{a}$ & -- & 1978.15 & 0.0168 \\
n-alkylbenzenes a & -- & 1208.18 & 0.0189 \\
\hline
\end{tabular}

\footnotetext{
a the values of n-alcohols, other aliphatic alcohols, n-alkylbenzenes are taken, and hydrocarbons directly from the work of Nguyen-Huynh et al. .[37] b the values are calculated by using eqs (11) \& (12). The regressed values of $u_{a \beta}$ and $w_{a \beta}$ are directly used in the calculation of $\varepsilon^{\mathrm{AB}} / \mathrm{k}$ and $\mathrm{K}^{\mathrm{AB}}$.
}

Table 5. Standard error ( $\mathrm{SE}^{\mathrm{SAFT}}$ ) per family for solubilities. of water in oxygenated organic phase $x_{i}^{\text {org }}$ and solubilities of oxygenated compounds in water $x_{i}^{\text {aq }}$.

\begin{tabular}{|c|c|c|c|c|c|c|}
\hline \multirow{2}{*}{ Family } & \multicolumn{3}{|c|}{$x_{i}^{\text {org }}$} & \multicolumn{3}{|c|}{$x_{i}^{a q}$} \\
\hline & Case 1 & Case 2 & Case 3 & Case 1 & Case 2 & Case 3 \\
\hline Ethers & 0.306 & 0.259 & 0.027 & 1.301 & 0.608 & 0.024 \\
\hline Aldehydes & 0.086 & 0.084 & 0.026 & 0.407 & 0.155 & 0.034 \\
\hline Ketones & 0.182 & 0.172 & 0.017 & 1.016 & 0.449 & 0.018 \\
\hline Formates & 0.110 & 0.143 & 0.013 & 0.911 & 0.371 & 0.033 \\
\hline Acetates & 0.156 & 0.116 & 0.020 & 1.154 & 0.617 & 0.015 \\
\hline Propionates/Butyrates & 0.132 & 0.118 & 0.018 & 1.141 & 0.228 & 0.009 \\
\hline Aliphatic acids & 0.405 & 0.248 & 0.033 & 1.646 & 0.257 & 0.043 \\
\hline n-alcohols & -- & -- & -- & 0.529 a & -- & $0.100^{b}$ \\
\hline n-alkanes & -- & -- & -- & 0.229 a & -- & $0.063^{b}$ \\
\hline
\end{tabular}




\begin{tabular}{ccccccc} 
n-alkylbenzenes & -- & -- & -- & $0.187^{\mathrm{a}}$ & -- & $0.020^{\mathrm{b}}$ \\
\hline Global SE & $\mathbf{0 . 1 8 7}$ & $\mathbf{0 . 1 6 0}$ & $\mathbf{0 . 0 2 1}$ & $\mathbf{1 . 1 0 3}^{\mathrm{c}}$ & $\mathbf{0 . 4 1 9}$ & $\mathbf{0 . 0 2 3 ^ { c }}$ \\
\hline
\end{tabular}

Note: Case 1, Case 2, Case 3 refer to "Predictive", " $1_{i j}+u_{\alpha \beta}+w_{\alpha \beta}$ ", and experimental data, respectively.

a The values are calculated by using the $" \mathrm{u}_{\alpha \beta}+\mathrm{w}_{\alpha \beta}$ " values originating from the work of Nguyen-Huynh et al.[37] These calculated values were presented in our previous work[59]. ${ }^{\mathrm{b}}$ The values are re-used from our previous work. [59] c The values are averaged without that of n-alcohols, n-alkanes, and n-alkylbenzenes.

Table 6. Standard error ( $\left.\mathrm{SE}^{\mathrm{SAFT}}\right)$ per family for infinite dilution activity coefficient in water $\gamma_{i}^{\mathrm{aq}, \infty}$ and n-octanol/water partition coefficient $\mathrm{K}_{\mathrm{ow}}$.

\begin{tabular}{|c|c|c|c|c|c|c|}
\hline \multirow{2}{*}{ Family } & \multicolumn{3}{|c|}{$\gamma_{i}^{a q, \infty}$} & \multicolumn{3}{|c|}{$K_{o w}$} \\
\hline & Case 1 & Case 2 & Case 3 & Case 1 & Case 2 & Case 3 \\
\hline Ethers & 1.112 & 0.484 & 0.019 & 1.163 & 0.406 & 0.146 \\
\hline Aldehydes & 0.376 & 0.132 & 0.013 & 0.392 & 0.246 & 0.146 \\
\hline Ketones & 0.952 & 0.413 & 0.015 & 1.039 & 0.527 & 0.146 \\
\hline Formates & 0.921 & 0.280 & 0.016 & 0.728 & 0.314 & 0.146 \\
\hline Acetates & 1.087 & 0.559 & 0.010 & 0.872 & 0.423 & 0.146 \\
\hline Propionates/Butyrates & 1.114 & 0.217 & 0.014 & 1.261 & 0.343 & 0.146 \\
\hline Aliphatic acids & 1.213 & 0.370 & 0.004 & 1.422 & 0.671 & 0.146 \\
\hline n-alcohols & $0.366^{\mathrm{a}}$ & -- & $0.011^{b}$ & $0.908^{a}$ & -- & $0.146^{\mathrm{b}}$ \\
\hline n-alkanes & $0.212^{a}$ & -- & $0.045^{b}$ & $0.818^{\text {a }}$ & -- & $0.146^{b}$ \\
\hline n-alkylbenzenes & $0.186^{\mathrm{a}}$ & -- & $0.020^{\mathrm{b}}$ & $0.405^{\mathrm{a}}$ & -- & $0.146^{b}$ \\
\hline Global SE $E^{\text {SAFT }}$ & $0.991^{c}$ & 0.377 & $0.013^{c}$ & $1.060^{c}$ & 0.469 & $0.146^{c}$ \\
\hline
\end{tabular}

Note: Case 1, Case 2, Case 3 refer to "predictive" approach, " $1_{i j}+u_{\alpha \beta}+w_{\alpha \beta}$ " approach, and experimental data, respectively. a The values are calculated by using the " $u_{\alpha \beta}+w_{\alpha \beta}$ " values originating from the work of NguyenHuynh et al.[37,84] These calculated values were presented in our previous work. [59] ${ }^{\mathrm{b}}$ The values are re-used from our previous work. [59] c The values are averaged without that of n-alcohols, n-alkanes, and nalkvlbenzenes. 


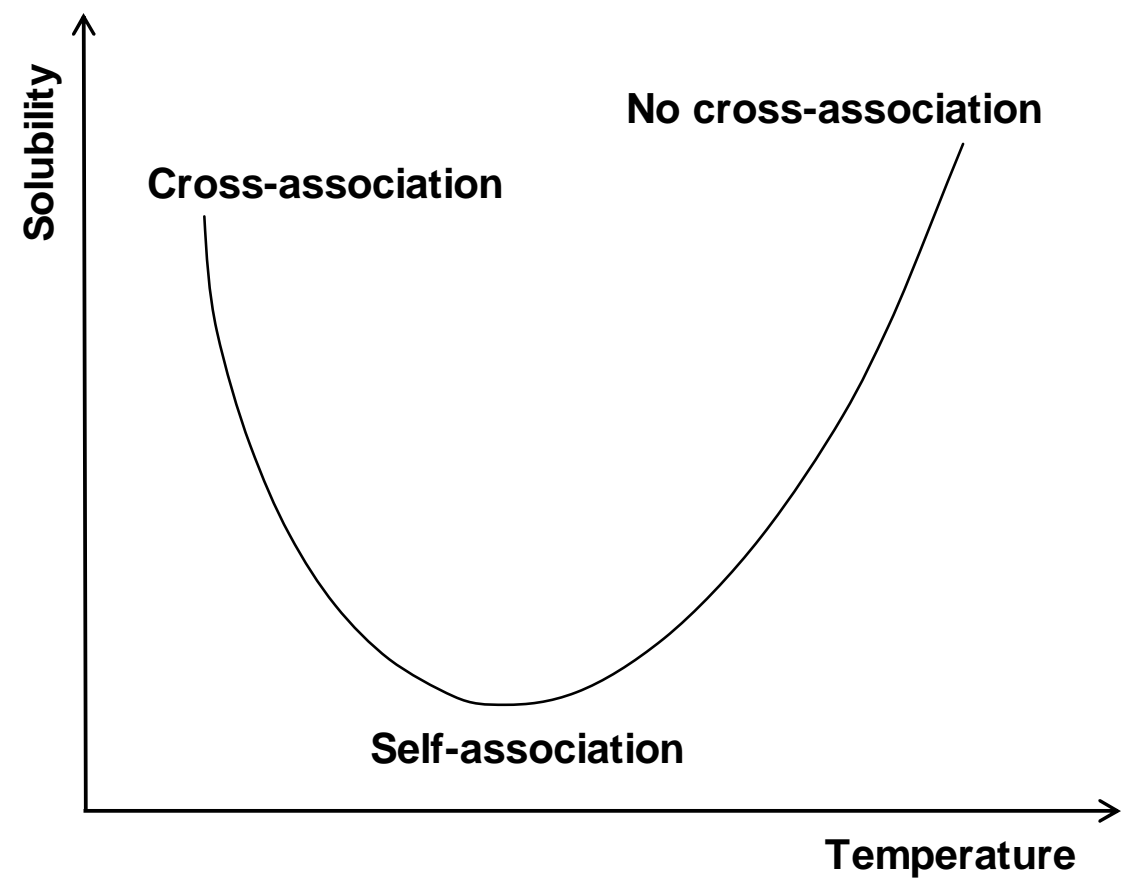

Figure 1. Illustration of the mutual solubility behaviour of oxygenated compounds/water mixture. 


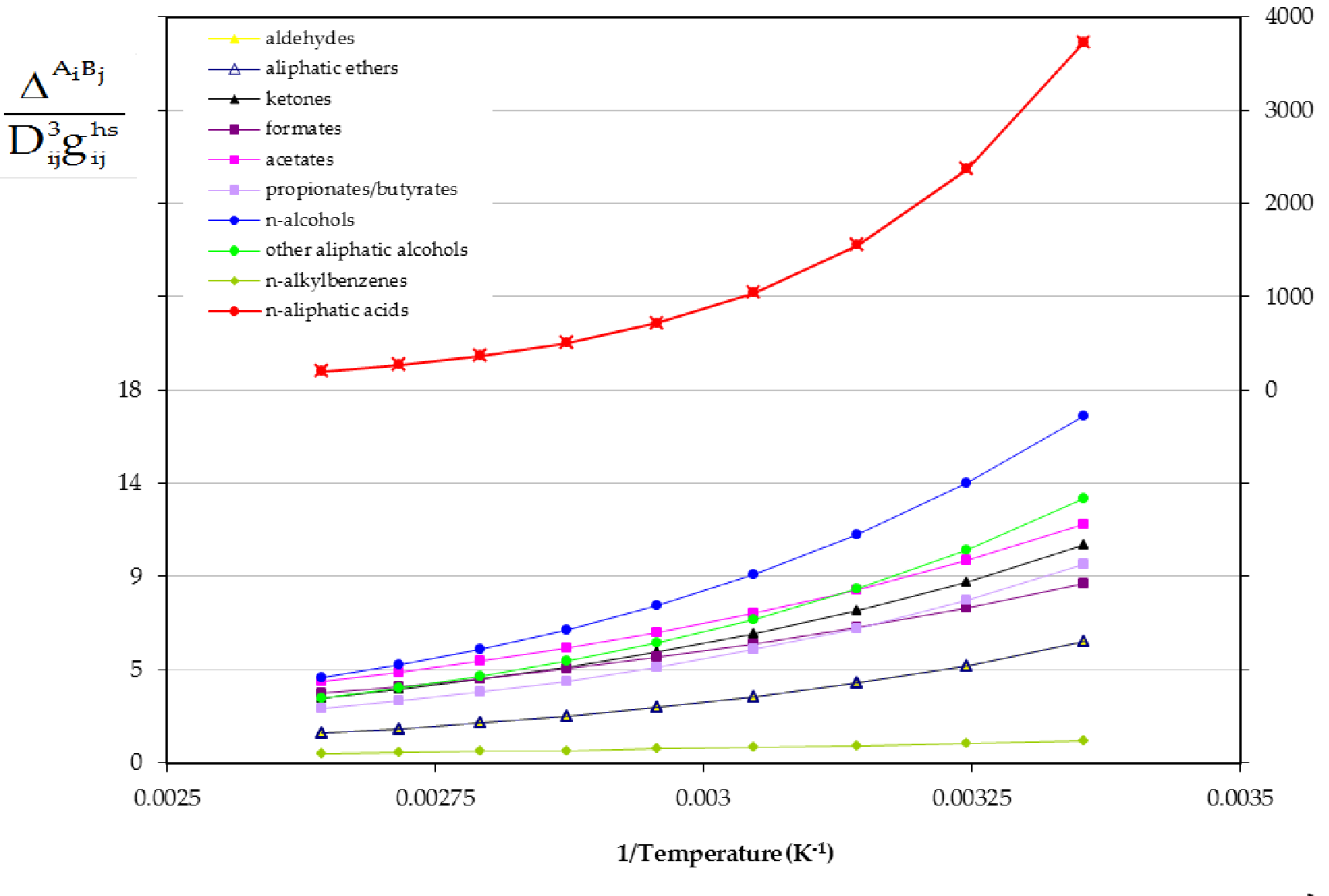

Figure 2. Association strength as a function of inverse temperature. 


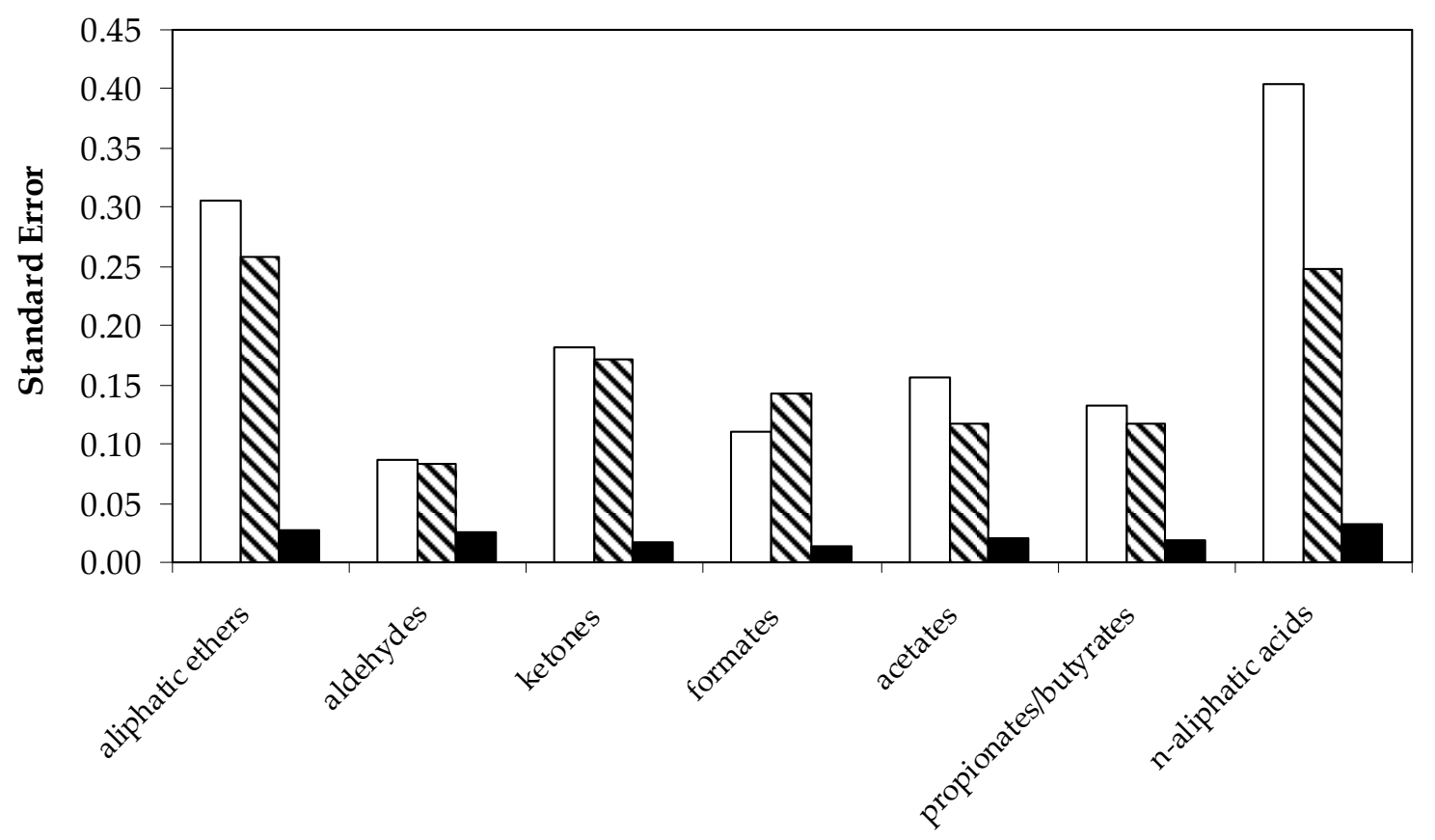

Figure 3. Standard error of solubilities of water in different oxygenated chemical families. Notation: "predictive" approach (white column), $" \mathrm{I}_{i j}+\mathrm{u}_{\alpha \beta}+\mathrm{w}_{\alpha \beta}$ " approach (diagonal column), experimental data (black column).

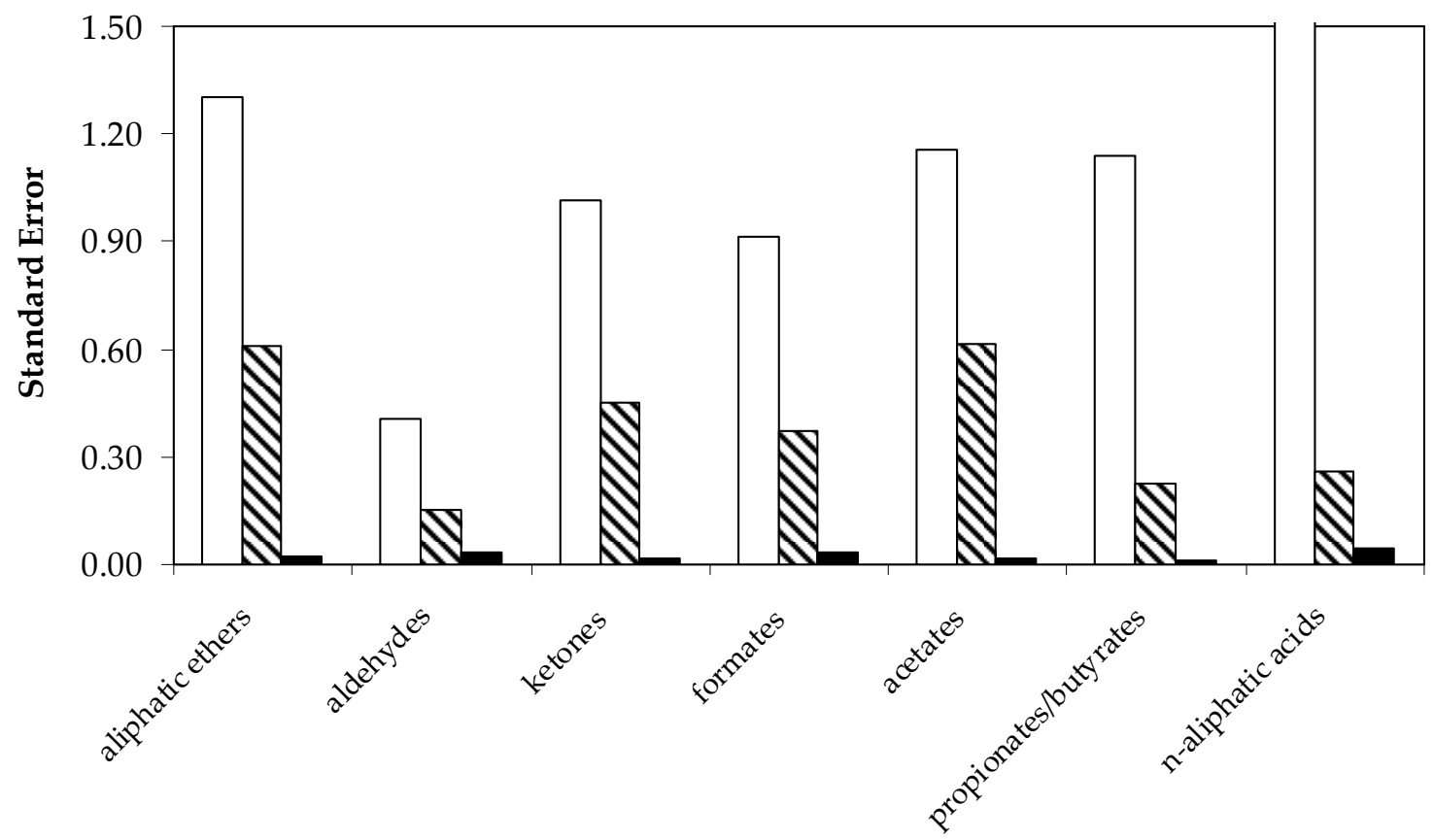

Figure 4. Standard error of solubility of oxygenated compounds in water. Notation: "predictive" approach (white column), ' $1_{i j}+u_{\alpha \beta}+w_{\alpha \beta}$ ' approach (diagonal column), experimental data (black column). 

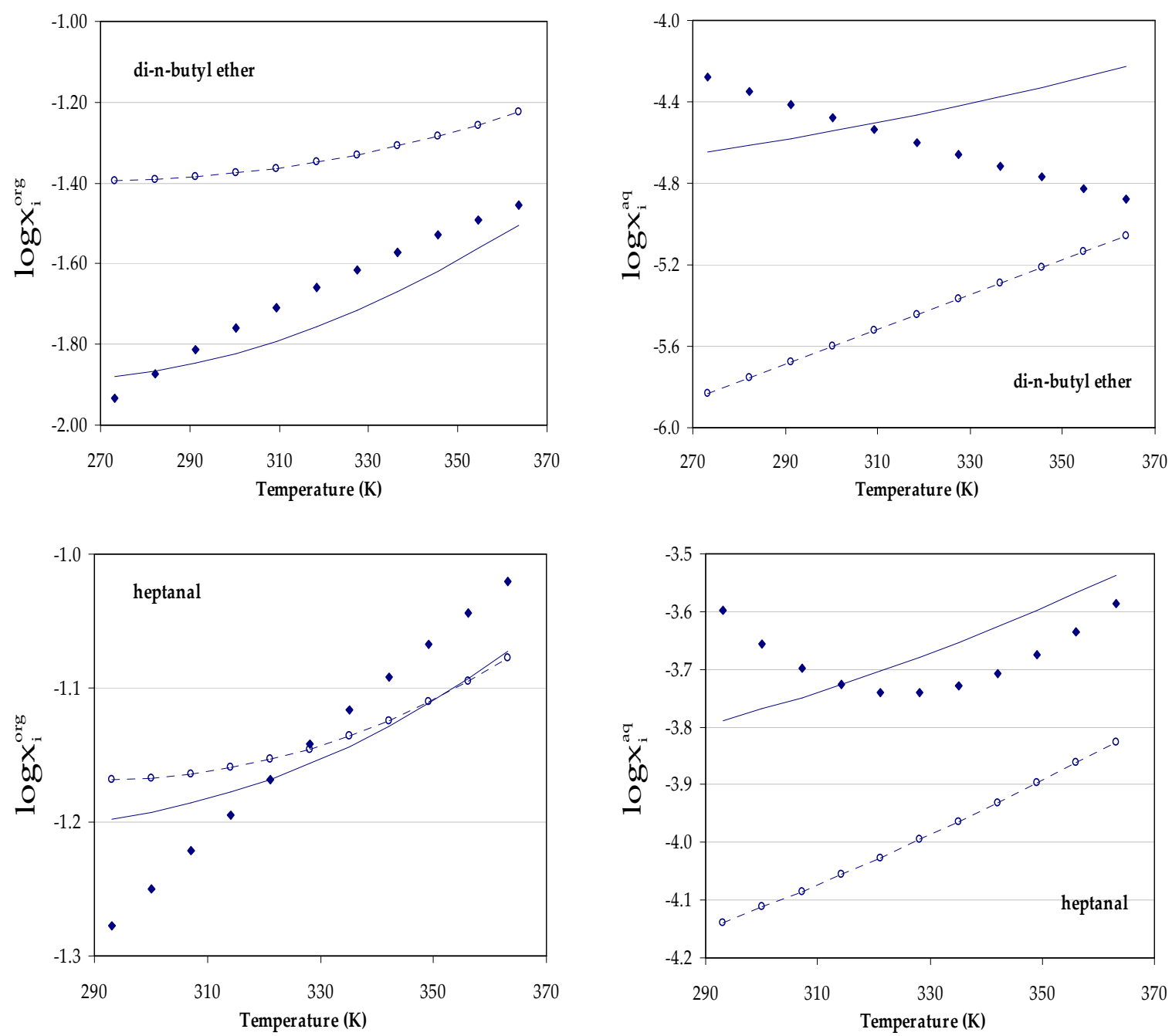

Figure 5. Some examples of the solubilities of water in organic phase $x_{i}^{\text {org }}$ and that of compounds in water $x_{i}^{\text {aq }}$. Notation: Experimental data (points), 'predictive' approach (point-dotted line), $1_{i j}+u_{\alpha \beta}$ $+\mathrm{w}_{\alpha \beta}$ " approach (solid line). 


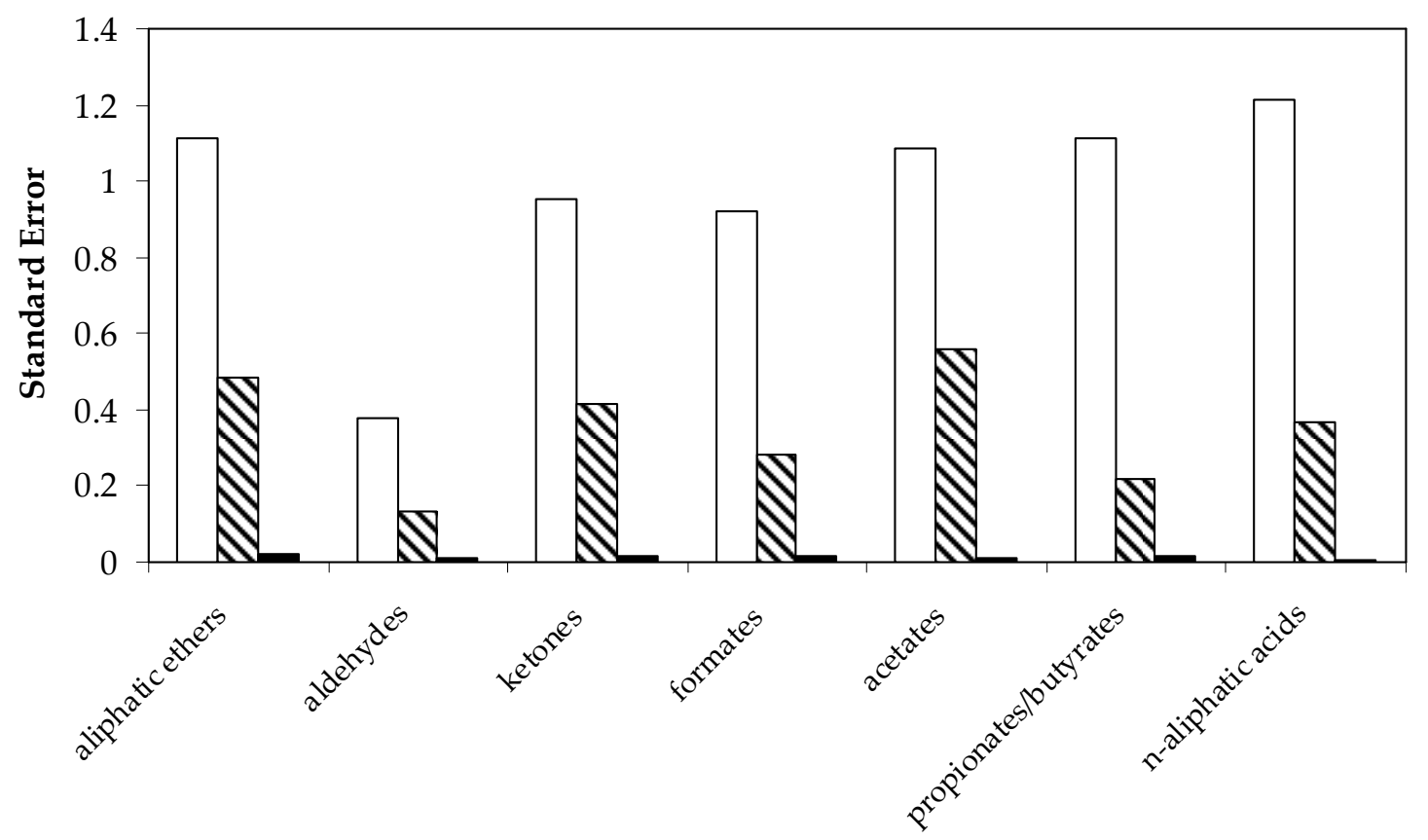

Figure 6. Infinite dilution activity coefficient in water $\gamma_{i}^{a, \infty, \infty}$. Notation: "predictive" approach (white column), $" 1_{i j}+u_{\alpha \beta}+w_{\alpha \beta}$ " approach (diagonal column), experimental data (black column). 

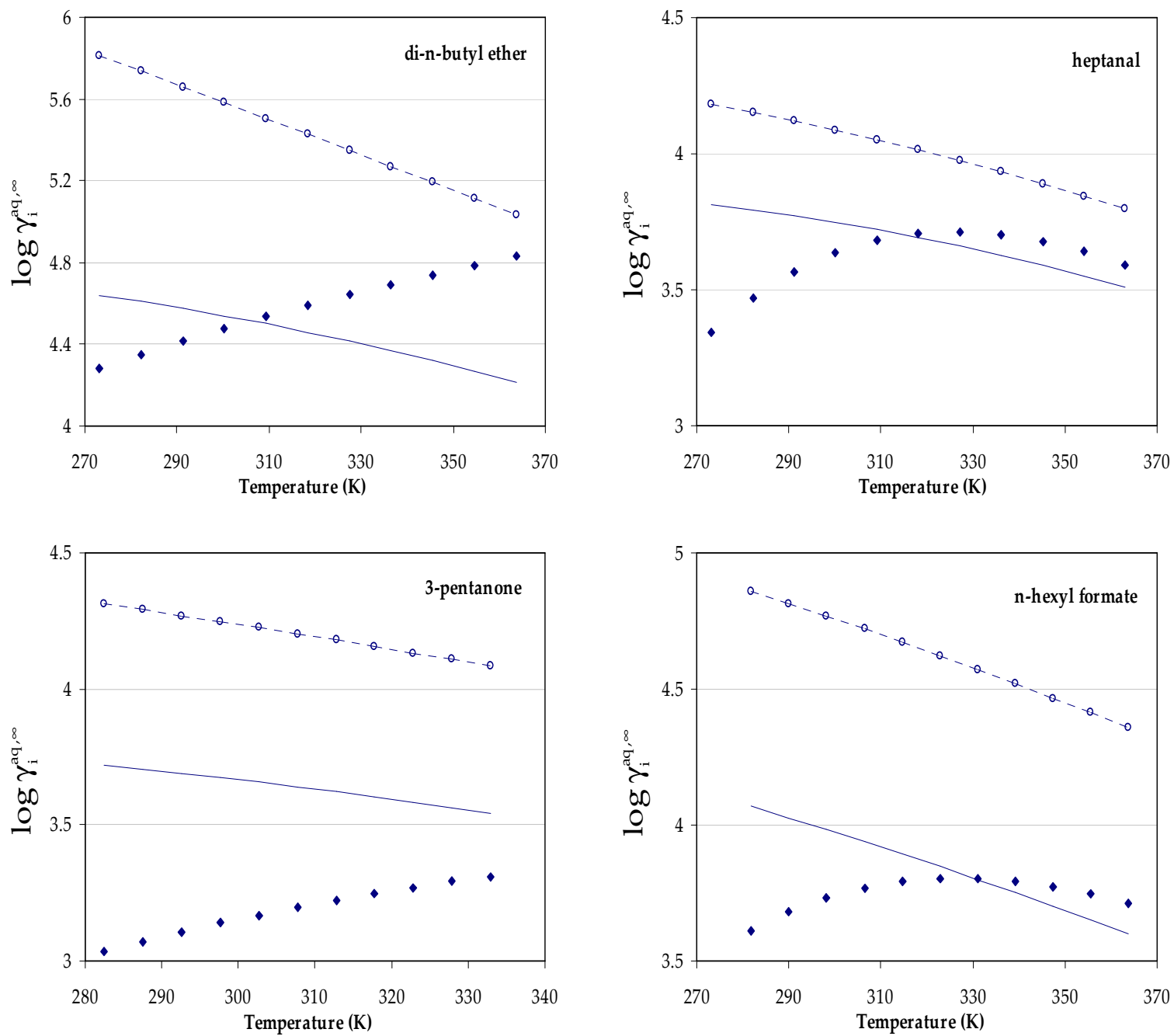

Figure 7. Some examples of infinite dilution activity coefficient in water $\gamma_{i}^{\text {aq, }, \infty}$. Notation: experimental data (points), "predictive" approach (point-dotted line), $" 1_{i j}+u_{\alpha \beta}+w_{\alpha \beta}$ "approach (solid line). 


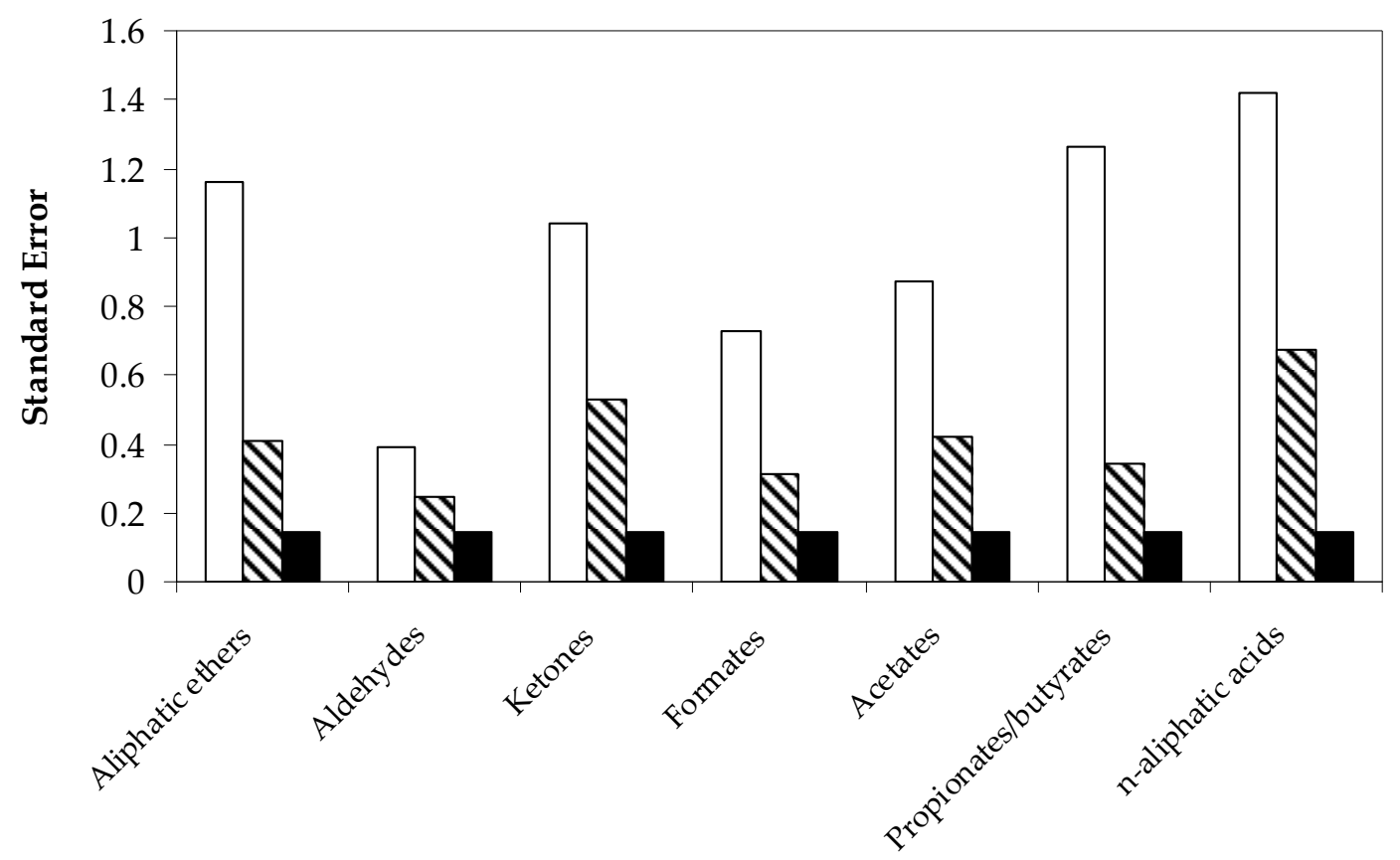

Figure 8. n-octanol/water partition coefficient $\mathrm{K}_{\mathrm{ow}}$. Notation: "predictive" approach (white column), " $1_{\mathrm{ij}}+\mathrm{u}_{\alpha \beta}+\mathrm{W}_{\alpha \beta}$ " approach (diagonal column), and experimental data (black column).

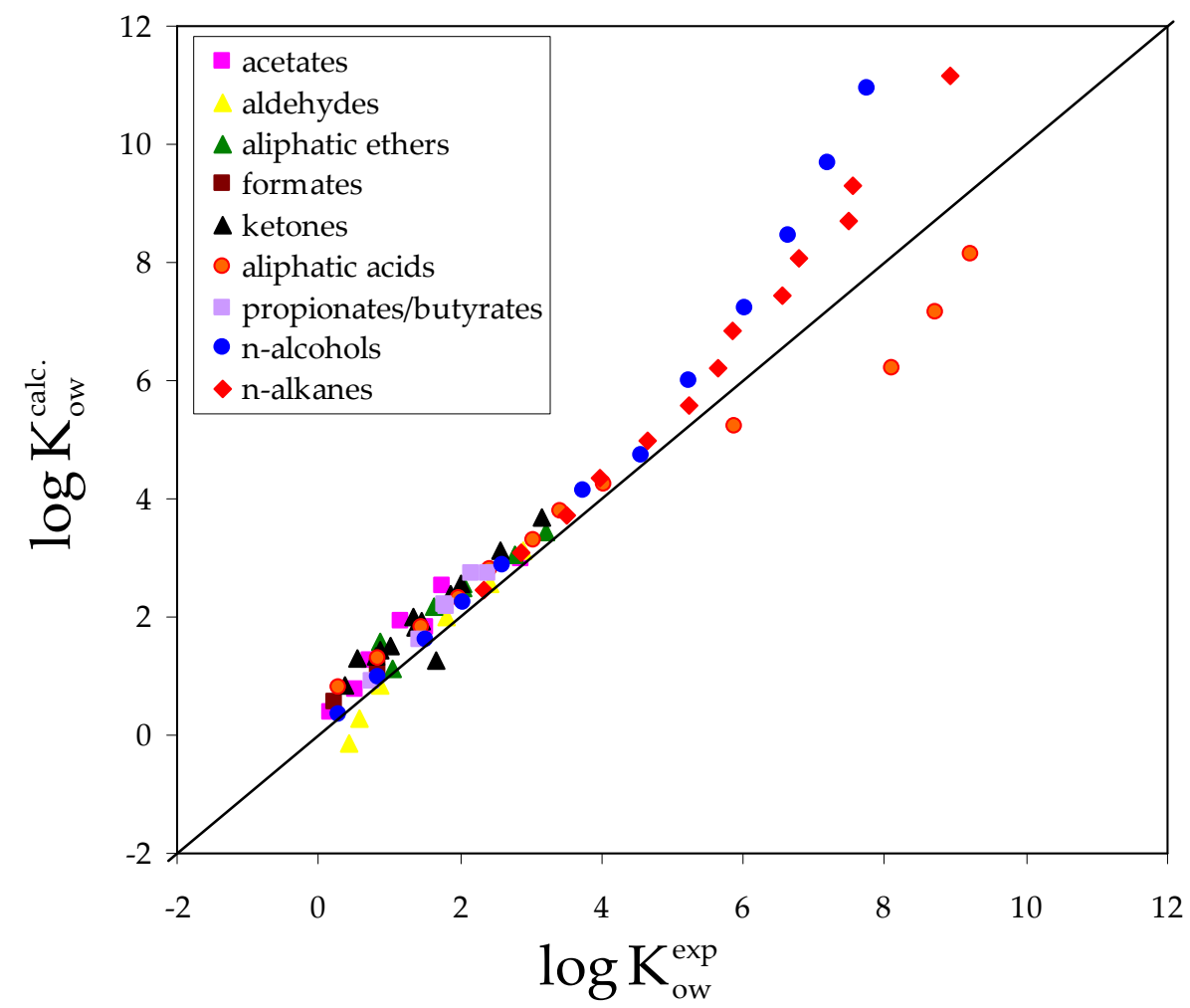

Figure 9. Parity diagram of $\mathbf{n}$-octanol/water partition coefficient $\mathrm{K}_{\mathrm{ow}}$. The values are calculated by using " $1_{\mathrm{ij}}+\mathrm{u}_{\alpha \beta}+\mathrm{w}_{\alpha \beta}$ " approach. The values of $\mathbf{n}$-alcohols and $\mathbf{n}$-alkanes are taken directly from our previous work[59]. 


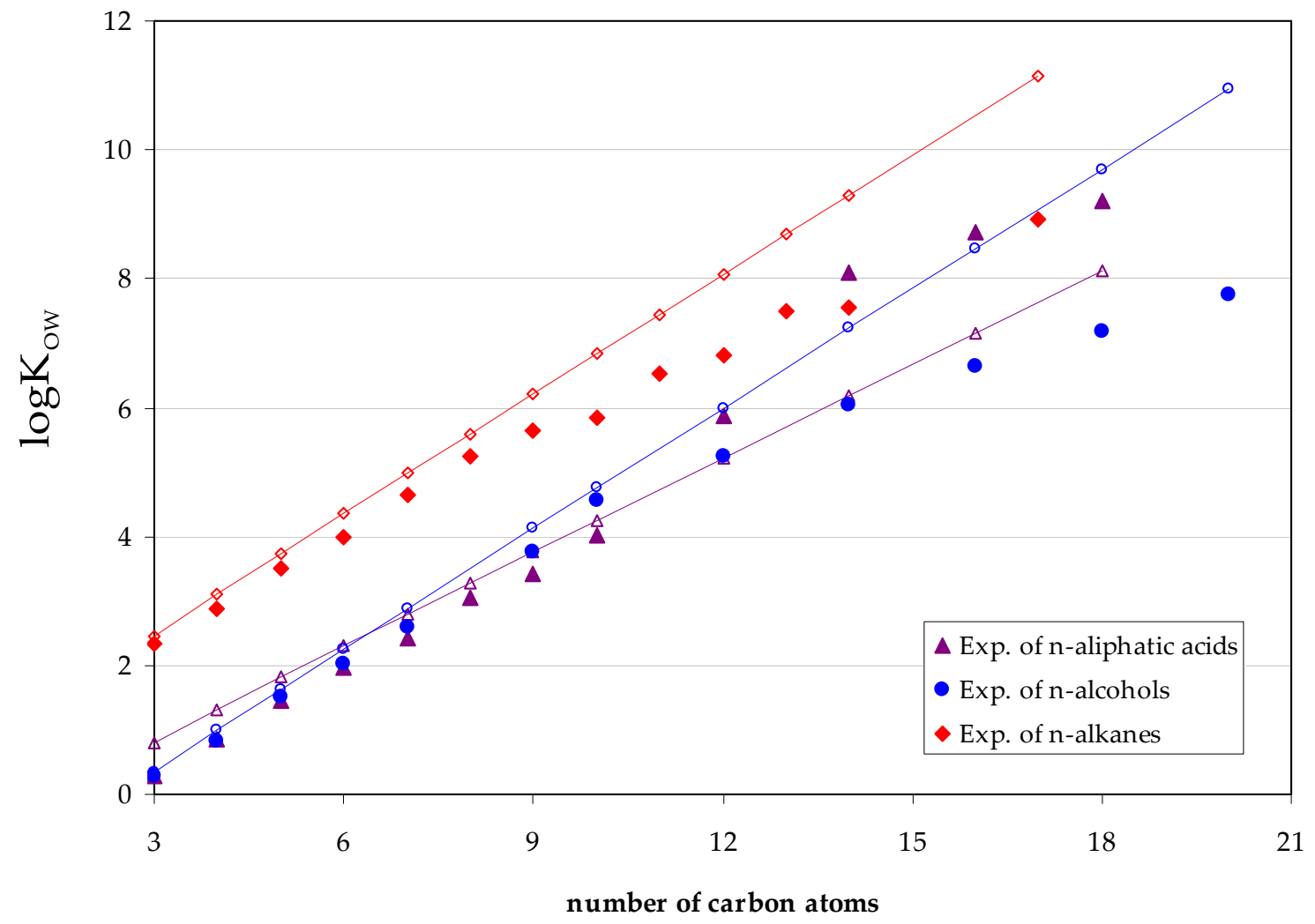

Figure 10. n-octanol/water partition coefficient $\mathrm{K}_{\mathrm{OW}}$ as a function of number of carbon atoms. Comparison of the experimental data (points) and the modelling results by the GC-PPC-SAFT model (lines) with the use of " $1_{i j}+u_{\alpha \beta}+w_{\alpha \beta}$ " approach for $n$-aliphatic acids. 


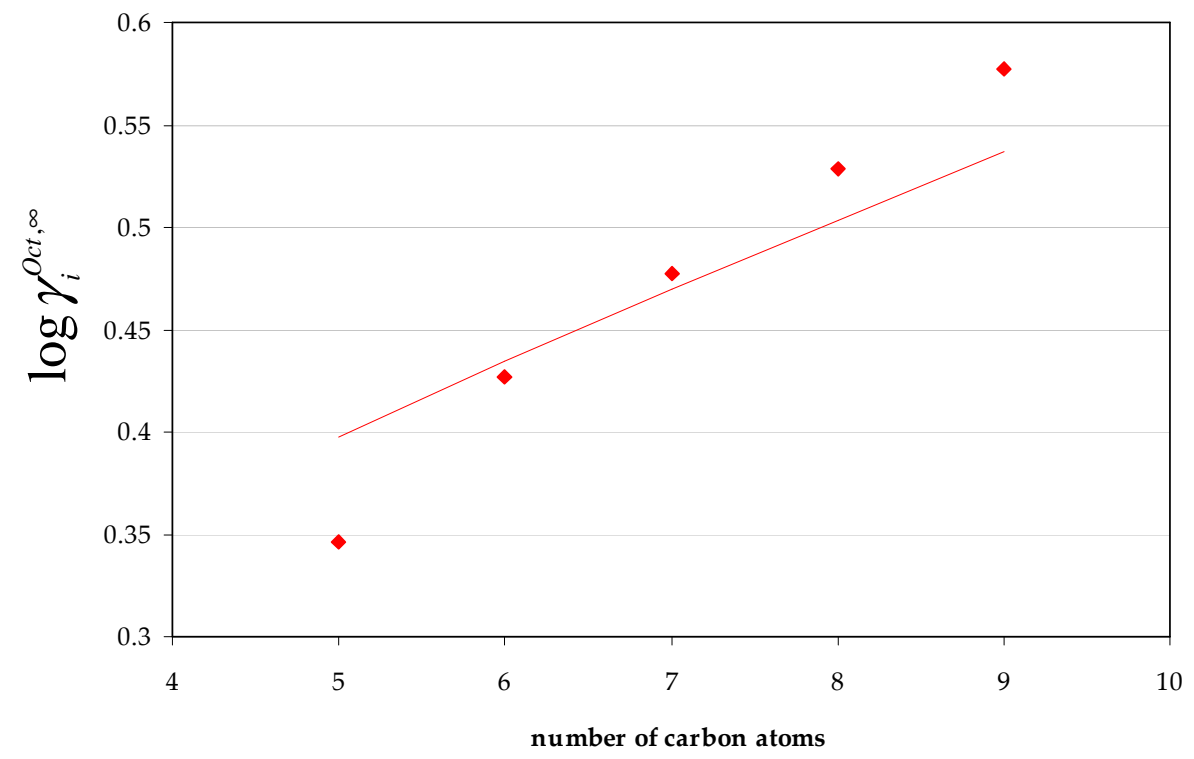

Figure 11. Infinite dilution activity coefficients of $\mathbf{n}$-alkanes in $\mathbf{n}$-octanol. The experimental data are taken from DETHERM[82]. The calculation is performed at $298.15 \mathrm{~K}$ without using $\mathrm{k}_{\mathrm{ij}}$. Notation: experimental data (symbols), and calculated values without using $\mathrm{k}_{\mathrm{ij}}$ (solid line). 


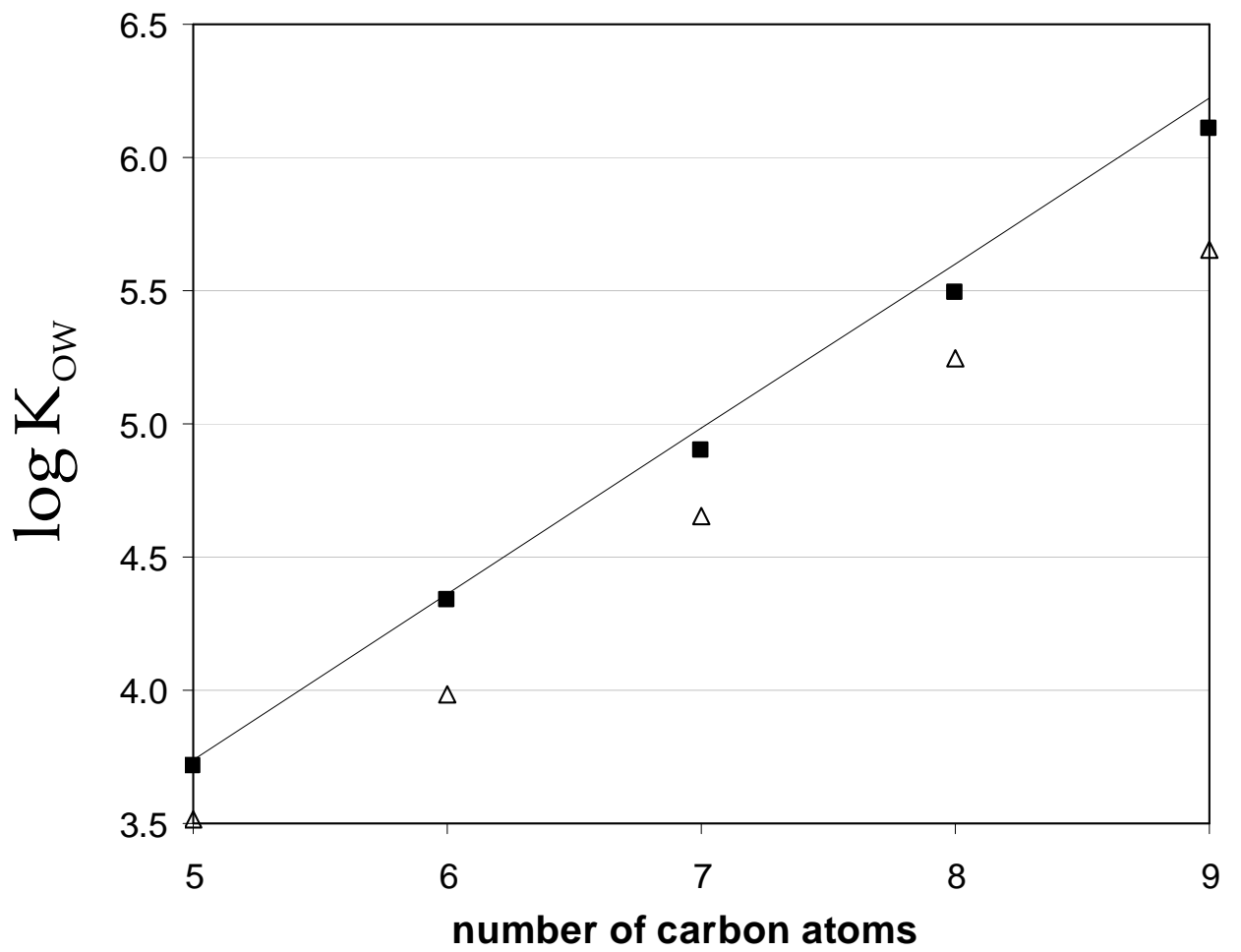

Figure 12. $n$-octanol/water partition coefficient $K_{o w}$ of $n$-alkanes as a function of number of carbon atoms. The experimental data are taken from references[93,97]. Notation: experimental data (triangles), pseudo-experimental data (solid squares), the calculated values without using $" 1_{\mathrm{ij}}+\mathrm{u}_{\alpha \beta}$ $+\mathrm{w}_{\alpha \beta} "$ (solid line). To be able to calculate pseudo-experimental data $K_{\mathrm{OW}}$ using (17), the experimental data for infinite dilution activity coefficients of $\mathbf{n}$-alkanes in water and in $\mathbf{n}$-octanol are taken from references,[94] $[95,97,99]$ the molecular volume of water and n-octanol is from DIPPR [100]. 
Reference List

[1] G.W. Huber, S. Iborra, A. Corman, Synthesis of transportation fuels from biomass: Chemistry, catalysts, and engineering, Chem. Rev., 106 (2006) 40444098 .

[2] M. Garcia-Perez, A. Chaala, H. Pakdel, D. Kretschmer, C. Roy, Characterization of bio-oils in chemical families, Biomass and Bioenergy, 31 (2007) 222-242.

[3] G.K. Georgeton, R.L. Smith, A.S. Teja, Application of Cubic Equations of State to Polar Fluids and Fluid Mixtures, in: Equations of State, American Chemical Society, 1986, pp. 434-451.

[4] E. Voutsas, P. Coutsikos, G. Kontogeorgis, Equations of state with emphasis on Excess Gibbs Energy Mixing Rules, in: Computer Aided Property Estimation for Process and Product Design, Elsevier, Amsterdam, 2004, pp. 434-451-

[5] M.J. Huron, J. Vidal, New mixing rules in simple equations of state for representing vapour-liquid equilibria of strongly non-ideal mixtures, Fluid Phase Equilib., 3 (1979) 255-271.

[6] J. Vidal, Mixing Rules and Excess Properties in Cubic Equations of State, CHEM ENG SCI, 33 (1978) 787-791.

[7] G.M. Wilson, Vapor-Liquid Equilibrium. XI. A New Expression for the Excess Free Energy of Mixing, J. Am. Chem. Soc., 86 (1964) 127-130.

[8] H. Renon, J.M. Prausnitz, Local composition in thermodynamic excess functions for liquid mixtures, AIChE J., 14 (1968) 135-144.

[9] D.S. Abrams, J.M. Prausnitz, Statistical thermodynamics of mixtures: a new expression for the Excess Gibbs free energy of partly or completely miscible systems, AIChE J., 21 (1975) 116-128.

[10] A. Fredenslund, R.L. Jones, J.M. Prausnitz, Group contribution estimation of Activity coefficients in nonideal liquid mixtures, AIChE J., 21 (1975) 1089-1099.

[11] J. Vidal, Thermodynamics: Applications in Chemical Engineering and the Petroleum Industry, Editions Technip, 2003.

[12] H. Orbey, S.I. Sandler, Vapor-Liquid Equilibria: Cubic Equations of State and Their Mixing Rules, Cambridge University Press, Cambridge, U.K., 1998. 
[13] G.M. Kontogeorgis, G.K. Folas, Thermodynamic Models for Industrial Applications: From Classical and Advanced Mixing Rules to Association Theories, Wiley, 2010.

[14] G.M. Kontogeorgis, P. Coutsikos, Thirty Years with EoS/GE Models - What Have We Learned?, Ind. Eng. Chem. Res., 51 (2012) 4119-4142.

[15] Y.S. Wei, R.J. Sadus, Equation of state for the calculation of fluid phase equilibria, AIChE J., 46 (2000) 169-

[16] G.N. Escobedo-Alvarado, S.I. Sandler, Study of EOS-G(ex) mixing rules for liquid-liquid equilibria, AIChE J., 44 (1998) 1178-1187.

[17] T. Ohta, H. Todoriki, T. Yamada, Representation of liquid-liquid equilibria at low and high pressures using the EOS-GE mixing rules, Fluid Phase Equilib., 225 (2004) 23-27.

[18] K. Knudsen, E.H. Stenby, J.G. Andersen, Modelling the influence of pressure on the phase behavior of systems containing water oil and nonionic surfactants, Fluid Phase Equilib., 93 (1994) 55-74.

[19] E.S.J. Rudolph, J.H. Langeveld, T. de Loos, J. de Swaan Arons, Phase behaviour of water+nonionic surfactant systems: experiments and modelling applying the Peng-Robinson equation of state with the Wong-Sandler mixing rules and the UNIQUAC gE-model, Fluid Phase Equilib., 173 (2000) 81-96.

[20] G.D. Ikonomou, M.D. Donohue, Thermodynamics of Hydrogen-bonded molecules: The associated Perturbed Anisotropic Chain Theory, AIChE J., 32 (1986) 1716-1725.

[21] H.P. Gros, S. Bottini, E.A. Brignole, A group contribution equation of state for associating mixtures, Fluid Phase Equilib., 116 (1996) 537-544.

[22] W.G. Chapman, K.E. Gubbins, G. Jackson, M. Radosz, SAFT: Equation-of-state solution model for associating fluids, Fluid Phase Equilib., 52 (1989) 31-38.

[23] W.G. Chapman, K.E. Gubbins, G. Jackson, M. Radosz, New Reference equation of state for associating liquids, Ind. Eng. Chem. Res., 29 (1990) 17091721.

[24] G.M. Kontogeorgis, E.C. Voutsas, I.V. Yakoumis, D.P. Tassios, An equation of state for associating fluids, Ind. Eng. Chem. Res., 35 (1996) 4310-4318.

[25] I. Tsivintzelis, A. Grenner, I.G. Economou, G.M. Kontogeorgis, Evaluation of the nonrandom hydrogen bonding (NRHB) theory and the simplified perturbed-chain-statistical associating fluid theory (sPC-SAFT). 2. Liquid- 
liquid equilibria and prediction of monomer fraction in hydrogen bonding systems, Ind. Eng. Chem. Res., 47 (2008) 5651-5659.

[26] S. Pereda, J.A. Awan, A.H. Mohammadi, A. Valtz, C. Coquelet, E.A. Brignole, D. Richon, Solubility of hydrocarbons in water: Experimental measurements and modeling using a group contribution with association equation of state (GCA-EoS), Fluid Phase Equilib., 275 (2009) 52-59.

[27] T.M. Soria, F.A. Stínchez, S. Pereda, S.B. Bottini, Modeling alcohol+water+hydrocarbon mixtures with the group contribution with association equation of state GCA-EoS, Fluid Phase Equilib., 296 (2010) 116124.

[28] I.V. Yakoumis, G.M. Kontogeorgis, E.C. Voutsas, E.M. Hendriks, D.P. Tassios, Prediction of phase equilibria in binary aqueous systems containing alkanes, cycloalkanes, and alkenes with the cubic-plus-association equation of state, Ind. Eng. Chem. Res., 37 (1998) 4175-4182.

[29] M. Kontogeorgis, Ten Years with the CPA (Cubic-Plus-Association) Equation of State. Part 2. Cross-Associating and Multicomponent Systems, Ind Eng Chem Res, 45 (2006) 4869-4878.

[30] M.B. Oliveira, J.A.P. Coutinho, A.J. Queimada, Mutual solubilities of hydrocarbons and water with the CPA EoS, Fluid Phase Equilib., 258 (2007) 58-66.

[31] M.B. Oliveira, F.R. Varanda, I.M. Marrucho, A.J. Queimada, J.A.P. Coutinho, Prediction of water solubility in biodiesel with the CPA equation of state, Ind. Eng. Chem. Res., 47 (2008) 4278-4285.

[32] M.B. Oliveira, M.J. Pratas, A.J. Queimada, J.A.P. Coutinho, Another look at the water solubility in biodiesels: Further experimental measurements and prediction with the CPA EoS, Fuel, 97 (2012) 843-847.

[33] A. Galindo, P.J. Whitehead, G. Jackson, A.N. Burgess, Predicting the highpressure phase equilibria of water plus n-alkanes using a simplified SAFT theory with transferable intermolecular interaction parameters, J. Phys. Chem., 100 (1996) 6781-6792.

[34] C. McCabe, A. Galindo, P.T. Cummings, Anomalies in the solubility of alkanes in near-critical water, J. Phys. Chem. B, 107 (2003) 12307-12314.

[35] L.F. Vega, F. Llovell, F.J. Blas, Capturing the solubility minima of n-alkanes in water by Soft-SAFT, J. Phys. Chem. B, 113 (2009) 7621-7630. 
[36] N. Patel, P. Paricaud, A. Galindo, G. Maitland, Prediction of the Salting Out effect of Strong Electrolytes on Water+Alkane Solutions, Ind. Eng. Chem. Res., $42 \quad$ (2003) 3809-3823.

[37] D. Nguyen-Huynh, J.C. de Hemptinne, R. Lugo, J.P. Passarello, P. Tobaly, Modeling Liquid-Liquid and Liquid-Vapor Equilibria of Binary Systems Containing Water with an Alkane, an Aromatic Hydrocarbon, an Alcohol or a Gas (Methane, Ethane, CO2 or H2S), Using Group Contribution Polar Perturbed-Chain Statistical Associating Fluid Theory, Ind. Eng. Chem. Res., 50 (2011) 7467-7483.

[38] M.N. Garcia-Lisbona, A. Galindo, G. Jackson, A.N. Burgess, An Examination of the Cloud Curves of LiquidГêÆLiquid Immiscibility in Aqueous Solutions of Alkyl Polyoxyethylene Surfactants Using the SAFT-HS Approach with Transferable Parameters, J. Am. Chem. Soc., 120 (1998) 4191-4199.

[39] N. Pedrosa, J.C. P+ámies, J.A.P. Coutinho, I.M. Marrucho, L.F. Vega, Phase Equilibria of Ethylene Glycol Oligomers and Their Mixtures, Ind. Eng. Chem. Res., 44 (2005) 7027-7037.

[40] N. Pedrosa, L.F. Vega, J.A.P. Coutinho, I.M. Marrucho, Modeling the Phase Equilibria of Poly(ethylene glycol) Binary Mixtures with soft-SAFT EoS, Ind. Eng. Chem. Res., 46 (2007) 4678-4685.

[41] S.H. Huang, M. Radosz, Equation of state for small, large, polydisperse and associating molecules, Ind. Eng. Chem. Res., 29 (1990) 2284-2294.

[42] Y.H. Fu, K.E. Sandler, A simplified SAFT equation of state for associating compounds and mixtures, Ind. Eng. Chem. Res., 34 (1995) 1897-

[43] T. Kraska, K.E. Gubbins, Phase Equilibria calculations with a modified SAFT equation of state: 1. Pure alkanes, alcohols and water, Fluid Phase Equilib., 35 (1996) 4727-4737.

[44] T. Kraska, K.E. Gubbins, Phase Equilibria calculations with a modified SAFT equation of state: 2.Binary mixtures of n-alkanes, 1-alcohols and water, Fluid Phase Equilib., 35 (1996) 4738-4746.

[45] F.J. Blas, L.F. Vega, Prediction of Binary and Ternary Diagrams Using the Statistical Associating Fluids Theory (SAFT) Equation of State, Ind. Eng. Chem. Res., 37 (1998) 660-674.

[46] A. Gil-Villegas, A. Galindo, P.J. Whitehead, S.J. Mills, G. Jackson, A.N. Burgess, Statistical Associating Fluid Theory for Chain Molecules with Attractive potentials of Variable Range, J. Chem. Phys., 106 (1997) 4168-4186. 
[47] J. Gross, G. Sadowski, Perturbed-Chain SAFT: An equation of state based on a perturbation theory for chain molecules, Ind. Eng. Chem. Res., 40 (2001) 12441260.

[48] N. von Solms, M.L. Michelsen, G.M. Kontogeorgis, Computational and physical performance of a modified PC-SAFT equation of state for highly asymmetric and associating mixtures, Ind. Eng. Chem. Res., 42 (2003) 10981105.

[49] E.K. Karakatsani, G.M. Kontogeorgis, I.G. Economou, Evaluation of the truncated perturbed chain-polar statistical associating fluid theory for complex mixture fluid phase equilibria, Ind. Eng. Chem. Res., 45 (2006) 60636074 .

[50] D. Nguyen-Huynh, J.P. Passarello, P. Tobaly, J.C. de Hemptinne, Application of GC-SAFT EOS to polar systems using a segment approach, Fluid Phase Equilib., 264 (2008) 62-75.

[51] J.C. de Hemptinne, J.M. Ledanois, Mougin P., A. Barreau, Select thermodynamic models for process simulation: A practical guide using a three steps methodology, Technip, 2012.

[52] S.P. Tan, H. Adidharma, M. Radosz, Recent Advances and Applications of Statistical Associating Fluid Theory, Ind. Eng. Chem. Res., 47 (2008) 8063-8082.

[53] W.G. Chapman, S.G. Sauer, D. Ting, A. Ghosh, Phase behavior applications of SAFT based equations of state - from associating fluids to polydisperse, polar copolymers, Fluid Phase Equilib., 217 (2004) 137-143.

[54] E.K. Karakatsani, I.G. Economou, Perturbed chain-statistical associating fluid theory extended to dipolar and quadrupolar molecular fluids, J. Phys. Chem. B, 110 (2006) 9252-9261.

[55] P. Jog, W.G. Chapman, Application of Wertheim's thermodynamic Perturbation theory to dipolar hard sphere chains, Mol. Phys., 97 (1999) 307319.

[56] F. Tumakaka, G. Sadowski, Application of the Perturbed-Chain SAFT equation of state to polar systems, Fluid Phase Equilib., 217 (2004) 233-239.

[57] I.G. Economou, Statistical Associating Fluid Theory: A succesful model for the calculation of Thermodynamic and Phase equilibrium properties of complex mixtures, Ind. Eng. Chem. Res., 41 (2002) 953-962. 
[58] E.A. Muller, K.E. Gubbins, Molecular-Based Equations of State for Associating Fluids: A Review of SAFT and Related Approaches, Ind. Eng. Chem. Res., 40 (2001) 2193-2211.

[59] T.B. Nguyen, J.C. de Hemptinne, B. Creton, G.M. Kontogeorgis, GC-PPCSAFT Equation of State for VLE and LLE of Hydrocarbons and Oxygenated Compounds. Sensitivity Analysis, Ind. Eng. Chem. Res., 52 (2013) 7014-7029.

[60] S. Tamouza, J.P. Passarello, P. Tobaly, J.C. de Hemptinne, Group contribution method with SAFT EOS applied to vapor liquid equilibria of various hydrocarbon series, Fluid Phase Equilib., 222-223 (2004) 67-76.

[61] T. Schnabel, J. Vrabec, H. Hasse, Unlike Lennard-Jones parameters for vaporliquid equilibria, Journal of Molecular Liquids, 135 (2007) 170-178.

[62] A.J. Haslam, A. Galindo, G. Jackson, Prediction of binary intermolecular potential parameters for use in modelling fluid mixtures, Fluid Phase Equilib., 266 (2008) 105-128.

[63] D. Nguyen-Huynh, J.P. Passarello, P. Tobaly, J.C. de Hemptinne, Modeling Phase Equilibria of Asymmetric Mixtures Using a Group-Contribution SAFT (GC-SAFT) with a k(ij) Correlation Method Based on London's Theory. 1. Application to CO2 + n-Alkane, Methane + n-Alkane, and Ethane + n-Alkane Systems, Ind. Eng. Chem. Res., 47 (2008) 8847-8858.

[64] D. Nguyen-Huynh, T.K.S. Tran, S. Tamouza, J.P. Passarello, P. Tobaly, J.C. de Hemptinne, Modeling Phase Equilibria of Asymmetric Mixtures Using a Group-Contribution SAFT (GC-SAFT) with a k(ij) Correlation Method Based on London's Theory. 2. Application to Binary Mixtures Containing Aromatic Hydrocarbons, n-Alkanes, CO2, N2, and H2S, Ind. Eng. Chem. Res., 47 (2008) 8859-8868.

[65] G.H. Hudson, J.C. McCoubrey, Intermolecular Forces between Unlike Molecules. A more complete form of the comining rules, Trans. Faraday Soc., 56 (1960) 761-

[66] J. Rozmus, J.C. de Hemptinne, P. Mougin, Application of GC-PPC-SAFT EoS to amine mixtures with a predictive approach, Fluid Phase Equilib., 303 (2011) 15-30.

[67] C. Held, A. Prinz, V. Wallmeyer, G. Sadowski, Measuring and modeling alcohol/salt systems, CHEM ENG SCI, 68 (2012) 328-339.

[68] A. Nann, C. Held, G. Sadowski, Liquid-Liquid Equilibria of 1Butanol/Water/IL Systems, Ind. Eng. Chem. Res., 52 (2013) 18472-18481. 
[69] A. Santos, M. Lopez de Haro, S.B. Yuste, Equation of state of nonadditive ddimensional hard-sphere mixtures, J CHEM PHYS, 122 (2005) 024514-

[70] P. Paricaud, Phase equilibria in polydisperse nonadditive hard-sphere systems, PHYS REV E, 78 (2008) 021202-

[71] S. Tamouza, J.P. Passarello, P. Tobaly, J.C. de Hemptinne, Application to binary mixtures of a group contribution SAFT EOS, Fluid Phase Equilib., 228229 (2005) 409-419.

[72] T. Boublik, Hard Sphere Equation of State, J. Chem. Phys., 53 (1970) 471-473.

[73] G.A. Mansoori, N.F. Carnahan, K.E. Starling, T.W.J. Leland, Equilibrium Thermodynamic Properties of the Mixture of Hard Spheres, J. Chem. Phys., 54 (1971) 1523-1525.

[74] J.A. Barker, D. Henderson, Perturbation Theory and Equation of State for Fluids: the Square well Potential, J. Chem. Phys., 47 (1967) 2856-2861.

[75] G. Jackson, W.G. Chapman, K.E. Gubbins, Phase equilibria of associating fluids: Spherical molecules with multiple bonding sites, Molec. Phys., 65 (1988) 1-31.

[76] K.E. Gubbins, C.H. Twu, Thermodynamics of Polyatomic Fluid Mixtures -1 Theory, CHEM ENG SCI, 33 (1978) 863-878.

[77] J.C. de Hemptinne, P. Mougin, A. Barreau, L. Ruffine, S. Tamouza, R. Inchekel, Application to petroleum engineering of statistical thermodynamics - Based equations of state, Oil \& Gas Sci. Tech. - Rev. IFP Energies nouvelles, 61 (2006) 363-386.

[78] T.-B. Nguyen, J.-C. de Hemptinne, B. Creton, G.M. Kontogeorgis, GC-PPCSAFT equation of state for VLE and LLE of hydrocarbons and oxygenated compounds. Sensitivity analysis, Ind. Eng. Chem. Res, 52 (2013) 7014-7029.

[79] J. Gross, G. Sadowski, Perturbed-Chain SAFT: An Equation of State Based on a Perturbation Theory for Chain Molecules, Ind. Eng. Chem. Res, 40 (2001) 12441260.

[80] S.O. Derawi, G.M. Kontogeorgis, M.L. Michelsen, E.H. Stenby, Extension of the cubic-plus-association equation of state to glycol-water cross-associating systems, Ind. Eng. Chem. Res., 42 (2003) 1470-1477.

[81] J.P. Wolbach, S.I. Sandler, Using molecular orbital calculations to describe the phase behavior of cross-associating mixtures, Ind. Eng. Chem. Res., 37 (1998) 2917-2928. 
[82] Detherm, Thermophysical properties of pure substances and mixtures, version 2011.3, 2011.

[83] http://help.scilab.org/docs/5.3.3/en US/datafit.html. 2011.

Ref Type: Online Source

[84] D. Nguyen-Huynh, J.-C. de Hemptinne, R. Lugo, J.-P. Passarello, P. Tobaly, Modeling Liquid-Liquid and Liquid-Vapor Equilibria of Binary Systems Containing Water with an Alkane, an Aromatic Hydrocarbon, an Alcohol or a Gas (Methane, Ethane, $\mathrm{CO}_{2}$ or $\mathrm{H}_{2} \mathrm{~S}$ ), Using Group Contribution Polar Perturbed-Chain Statistical Associating Fluid Theory, Ind. Eng. Chem. Res, 50 (2011) 7467-7483.

[85] A. Maczynski, D.G. Shaw, M. Goral, B. Wisniewska-Goclowska, IUPAC-NIST solubility data series. 82. Alcohols with water-revised and updated: Part 5. C8-C-17 alcohols with water, J. Phys. Chem. Ref. Data, 36 (2007) 685-731.

[86] A. Maczynski, D.G. Shaw, M. Goral, B. Wisniewska-Goclowska, IUPAC-NIST Solubility Data Series. 86. Ethers and ketones with water. Part 4. C-4 and C-5 ketones with water, J. Phys. Chem. Ref. Data, 37 (2008) 1517-1574.

[87] A. Maczynski, D.G. Shaw, M. Goral, B. Wisniewska-Goclowska, IUPAC-NIST Solubility Data Series. 86. Ethers and ketones with water. Part 6. C-7-C-12 ketones with water, J. Phys. Chem. Ref. Data, 37 (2008) 1611-1653.

[88] E.C. Voutsas, D.P. Tassios, Prediction of Infinite-Dilution Activity Coefficients in Binary Mixtures with UNIFAC. A Critical Evaluation, Ind. Eng. Chem. Res., 35 (1996) 1438-1445.

[89] R.P. Gerber, R.d. Soares, Prediction of Infinite-Dilution Activity Coefficients Using UNIFAC and COSMO-SAC Variants, Ind. Eng. Chem. Res., 49 (2010) 7488-7496.

[90] M.H. Abraham, H.S. Chadha, G.S. Whiting, R.C. Mitchell, Hydrogen bonding.32. An analysis of water-octanol and water-alkane partitioning and the $\Delta \log$ p parameter of seller, J. Pharm. Sci., 83 (1994) 1085-1100.

[91] F. Spafiu, A. Mischie, P. Ionita, A. Beteringhe, T. Constantinescu, A.T. Babalan, New Alternatives for Estimating the Octanol/Water Partition Coefficient and Water Solubility for Volatile Organic Compounds Using GLC Data (Kovàst Retention Indices), ARKIVOC, 2009 (2009) 174-194.

[92] P.V. Khadikar, D. Mandloi, A.V. Bajaj, S. Joshi, QSAR Study on Solubility of Alkanes in Water and Their Partition Coefficients in Different Solvent Systems Using PI Index, Bioorganic \& Medicinal Chemistry Letters, 13 (2003) 419-422. 
[93] C. McAuliffe, Solubility in Water of Paraffin, Cycloparaffin, Olefin, Acetylene, Cycloolefin, and Aromatic Hydrocarbons, J. Phys. Chem, 70 (1966) 1267-1275.

[94] J.H. Rytting, L.P. Huston, T. Higuchi, Thermodynamic group contributions for hydroxyl, amino, and methylene groups, Journal of Pharmaceutical Sciences, 67 (1978) 615-618.

[95] L.C. Price, Aqueous solubility of petroleum as applied to its origin and primary migration, American Association of Petroleum Geologists (AAPG) Bulletin, 60 (1976) 213-244.

[96] M. Tu, D. Fei, Y. Liu, J. Wang, Phase Equilibrium for Partially Miscible System of Octane-Water, Gaoxiao Huaxue Gongcheng Xuebao, 12 (1998) 325-330.

[97] J. Tolls, J. van Dijk, E.J.M. Verbruggen, J.L.M. Hermens, B. Loeprecht, G. Schüürmann, Aqueous Solubility-Molecular Size Relationships: A Mechanistic Case Study Using C10- to C19-Alkanes, The Journal of Physical Chemistry A, 106 (2002) 2760-2765.

[98] H.D. Nelson, C.L. de Ligny, The Determination of the Solubilities of Some nAlkanes in Water at Different Temperatures, by Means of Gas Chromatography, Recl. Trav. Chim. Pays Bas, 87 (1968) 528-544.

[99] R.Ya. Krasnoshchekova, M.Ya. Gubergrits, Solubility of Paraffin Hydrocarbons in Fresh and Salt Water, Neftekhiniya, 13 (1973) 885-888.

[100] J. R. Rowley, W. Wilding, V, J. L. Oscarson, Y. Yang, N. F. Giles. DIPPR (R) Data Compilation of Pure Chemical Properties. Design Institute for Physical Properties Data (DIPPR-AIChE) . 2011.

Ref Type: Electronic Citation 